\title{
Predicting the equity market with option- implied variables
}

Article

Accepted Version

Hollstein, F., Prokopczuk, M., Tharann, B. and Wese Simen, C. (2019) Predicting the equity market with option-implied variables. European Journal of Finance, 25 (10). pp. 937-965. ISSN 1466-4364 doi:

https://doi.org/10.1080/1351847X.2018.1556176 Available at https://centaur.reading.ac.uk/81483/

It is advisable to refer to the publisher's version if you intend to cite from the work. See Guidance on citing.

To link to this article DOI: http://dx.doi.org/10.1080/1351847X.2018.1556176

Publisher: Taylor and Francis

All outputs in CentAUR are protected by Intellectual Property Rights law, including copyright law. Copyright and IPR is retained by the creators or other copyright holders. Terms and conditions for use of this material are defined in the End User Agreement.

\section{www.reading.ac.uk/centaur}

\section{CentAUR}

Central Archive at the University of Reading 
Reading's research outputs online 


\title{
Predicting the Equity Market with Option-Implied
}

\section{Variables* $^{*}$}

\author{
Fabian Hollstein ${ }^{\dagger}$, Marcel Prokopczuk ${ }^{\dagger, \ddagger}$, Björn Tharann, ${ }^{\dagger}$ \\ and Chardin Wese Simen ${ }^{\ddagger}$
}

\begin{abstract}
We comprehensively analyze the predictive power of several option-implied variables for monthly S\&P 500 excess returns and realized variance. The correlation risk premium $(C R P)$ and the variance risk premium $(V R P)$ emerge as strong predictors of both excess returns and realized variance. This is true both in- and out-of-sample. Our results also reveal that statistical evidence of predictability does not necessarily lead to economic gains. However, a timing strategy based on the $C R P$ leads to utility gains of more than $5.03 \%$ per annum. Forecast combinations provide stable forecasts for both excess returns and realized variance, and add economic value.
\end{abstract}

JEL classification: G10, G11, G17

Keywords: Equity Premium, Option-Implied Information, Portfolio Choice, Predictability, Timing Strategies

\footnotetext{
${ }^{*}$ We are grateful to Chris Adcock (the editor), an anonymous associate editor, two anonymous referees, Duygu Zirek (discussant), Steven Clark, and other seminar participants at the Financial Management Association Annual Meeting 2017 for valuable comments. We thank Fabian Bätje, and Maik Dierkes for helpful comments and suggestions. Contact: hollstein@fmt.uni-hannover.de (F. Hollstein), prokopczuk@fmt.uni-hannover.de (M. Prokopczuk), tharann@fmt.uni-hannover.de (B. Tharann), and c.wese-simen@icmacentre.ac.uk (C. Wese Simen).

${ }^{\dagger}$ Leibniz University Hannover, Koenigsworther Platz 1, D-30167 Hannover, Germany.

${ }^{\ddagger}$ ICMA Centre, Henley Business School, University of Reading, Reading, RG6 6BA, U.K.
} 


\section{Introduction}

A growing literature, e.g. Jiang \& Tian (2005), Bollerslev et al. (2009), and Driessen et al. (2013), documents the predictive power of option-implied variables for equity excess returns and realized variance. The growing number of option-implied predictors raises several questions: Which variables really forecast market excess returns? Do the variables that predict market excess returns also forecast realized variance? Does predictability lead to economic gains? These are some of the questions we want to study.

The main contribution of this paper is to provide a comprehensive analysis of the forecasting ability of variables separately proposed in the recent literature on option-implied predictors. We perform our analysis following the methodological background of Goyal \& Welch (2008). Importantly, we do not only analyze return predictability, but consider the predictability of variance at the same time. This is important from a portfolio choice perspective, since both quantities are needed for a portfolio decision. As such, we do not only consider statistical predictability, but also analyze the economic significance of return and variance predictability. We find that several variables, including the correlation risk premium $(C R P)$ and the variance risk premium $(V R P)$, predict the monthly excess return of the S\&P 500. This is the case both in- and out-of-sample. We also show that both the $C R P$ and the $V R P$ predict not only the market excess return but also its realized variance. On the other hand, while most predictors are based on the option-implied moments of Bakshi et al. (2003), we note that the risk-neutral moments themselves have strong predictive power only for realized variance but not for the market excess return.

When studying the economic effects of the documented predictability in the context of portfolio choice, we find that relative to the agent who assumes that the mean and variance of the market return are unpredictable, a mean-variance agent with a risk-aversion coefficient of 3 who uses the information content of the $C R P$ would realize utility gains of $5.03 \%$ per 
annum (p.a.). Relatedly, we find that a return timing strategy based on the $V R P$ leads to lower utility gains than those afforded by the strategy based on the recursive mean. This indicates that the statistical evidence of predictability of excess returns and realized variance, respectively, by the $V R P$ does not always translate into economic gains. We conjecture that this result is due to the fact that individual variables lead to a large dispersion in the forecast estimation. Forecast combinations instead appear to generate stable forecasts for both excess returns and realized variance, and add economic value. Further, we link this result also to the sign-switching behavior of the $V R P$ around economically important periods.

A variable is considered to have predictive power if it passes two tests. First, it has to generate statistically significant forecasts. In this case the variable contains key information about the variation in the market risk premium and the realized variance, respectively. Bollerslev et al. (2009) and Drechsler \& Yaron (2011) argue that time-varying economic uncertainty is captured by the variance risk premium and, thus, affects the variation in the market risk premium. Driessen et al. (2009, 2013) state that the time-varying correlation risk is linked to economic uncertainty and, thus, also relates to the market price of return risk. Second, the variable needs to add economic value. Since the predictability, measured by the $R^{2}$ is, in general, small in magnitude, the question arises whether it is economically meaningful. Does an investor obtain an increase in utility by taking the variable into account? This aspect is often ignored in the existing literature. Our results show that the $C R P$ emerges as the only predictor that passes both tests.

For robustness, we analyze the predictability of different specifications of the $V R P$. We follow Andersen \& Bondarenko (2010), Andersen et al. (2015), and Feunou et al. (2015) and decompose the total variance risk premium into the downside and upside components. The results show that the upside and downside variance risk premia significantly predict excess returns and realized variance in-sample and add economic value based on a timing strategy.

Our work relates to the literature on the predictability of the market excess return 
and/or its associated realized variance using option-implied quantities. Bollerslev et al. (2009) document the predictive power of the variance risk premium for S\&P 500 excess returns, and Bollerslev et al. (2014) document similar results for a broad range of international equity indices. Pyun (2016) provides evidence of a weak out-of-sample performance of the variance risk premium for S\&P 500 excess returns. Driessen et al. (2009, 2013) show that the correlation risk premium predicts S\&P 500 excess returns, whereas Cosemans (2011) points out that the correlation risk premium and the systematic part of individual variance risk premia drive the predictive power of the variance risk premium for market excess returns. Zhou (2013) documents the predictive power of the S\&P 500 implied correlation index for S\&P 500 index returns. Xing et al. (2010) find that the option-implied smirk contains information about the cross-section of equity returns. Cremers \& Weinbaum (2010) document that deviations from the put-call parity, measured as the difference in implied volatility between pairs of call and put options of U.S. stocks, contain information about the cross-section of stock returns and have predictive power for these. Rehman \& Vilkov (2012) and Stilger et al. (2016) show that implied skewness of individual U.S. stocks has predictive power for future returns. Bali et al. (2011) introduce an option-implied generalized measure of riskiness and provide evidence for its predictive power for the cross-section of individual stock returns. Bali et al. (2012) and Bali et al. (2015) extend the analysis and document the predictive power of the generalized measure for economic downturns and future market excess returns. Leiss et al. (2015) and Leiss \& Nax (2018) examine non-parametric risk-neutral densities from S\&P 500 index options. Leiss \& Nax (2018) provide evidence for the predictive power of an option-implied riskiness measure based on Foster \& Hart (2009) for future downturns. Bali et al. (2017) document a relation between the risk-neutral moments of Bakshi et al. (2003) and expected stock returns.

Jiang \& Tian (2005) and Kourtis et al. (2016) establish the forecasting power of the S\&P 500 option-implied variance for realized variance. The above mentioned studies use 
different sample periods and statistical techniques to document their results, thus making the interpretation and comparison of the findings somewhat difficult. We use a common sample period and recent developments in the literature on predictability to thoroughly analyze all these variables.

Our study also relates to the literature on the economic value of predictability. Typically, the literature analyzes the implications of return predictability for a return timing strategy (e.g., Campbell \& Thompson, 2008; Çakmaklı \& van Dijk, 2016). Similarly, studies on realized variance predictability only explore the implications for a volatility/variance timing strategy (Fleming et al., 2001). Unlike these studies, we jointly study the impact of return and variance timing. This is important because in a mean-variance framework, the optimal portfolio weight invested in the risky asset depends on both the expected return and the expected realized variance. If a forecasting variable predicts both the market excess return and the realized variance, it might be potentially important to account for these two effects when computing the optimal weight.

The remainder of this paper proceeds as follows. Section II. introduces the data and explains the construction of the main variables. Section III. presents the main empirical results. Section $I V$. discusses some further results. Section $V$. provides additional results. Finally, Section VI. concludes.

\section{Data and Methodology}

\section{II.A Data}

We obtain our data from three distinct sources. First, we retrieve the monthly time series of the S\&P 500 total return index as well as the corresponding dividend payments from the Center for Research in Security Prices (CRSP) database. Second, we obtain S\&P 
500 index option data from OptionMetrics. The OptionMetrics dataset contains information about option contracts available in the market as well as standardized options, both of which are useful for our analysis (see Section II.B). Third, we use intraday data on the S\&P 500 index sampled at the 5-minute frequency from Thomson Reuters Tick History (TRTH). In sampling the intraday data, we focus on the normal trading hours, i.e. from 09:30 AM to 04:00 PM Eastern Daylight Time (EDT). Our sample period extends from January 1996 to December 2014. It is worth pointing out that although the CRSP database covers a period starting before 1996, this is not the case for the OptionMetrics and TRTH. Starting our sample in January 1996 allows us to guarantee the availability of data from all three databases.

\section{II.B Variables}

Armed with the dataset introduced above, we are now able to construct our main variables.

Market Excess Return We compute the excess return on the S\&P 500 index by subtracting the riskless rate for the corresponding period from the total return on the equity index:

$$
E R_{t+1}=12 \times \log \left(\frac{P_{t+1}}{P_{t}}\right)-r f_{t}
$$

where $E R_{t+1}$ is the (annualized) monthly excess return on the S\&P 500 index at the end of month $t+1$. $P_{t+1}$ and $P_{t}$ denote the total return price index at the end of months $t+1$ and $t$, respectively. $r f_{t}$ refers to the (annualized) riskless rate observed at the end of month $t .^{1}$ Following Goyal \& Welch (2008), we use the 1-month T-bill rate to proxy for the riskless rate.

\footnotetext{
${ }^{1}$ Throughout this paper, we use the convention that the riskless rate is given the subscript for the time when it is observed. Thus, the riskless rate is observed at time $t$ even though it is realized at time $t+1$.
} 
Realized Variance In order to estimate the realized variance of the stock market, we exploit developments in the literature on high-frequency financial econometrics. Andersen et al. (2003) show that by sampling data at the intraday level, one can improve the accurate measurement of realized variance. Building on this insight, we use intraday prices sampled at the 5-minute frequency to compute the realized variance of the asset:

$$
R V_{t+1}=\frac{360}{N} \times\left[\sum_{i=1}^{N}\left(\sum_{j=1}^{m-1} \log \left(\frac{S_{t+\frac{i}{N}, j+1}}{S_{t+\frac{i}{N}, j}}\right)^{2}\right)+\log \left(\frac{S_{t+\frac{i}{N}, 1}}{S_{t+\frac{i-1}{N}, m}}\right)^{2}\right]
$$

where $R V_{t+1}$ is the realized variance at the end of month $t+1$. The first term to the right of the equality sign simply annualizes the variance estimate, where $N$ is the number of days between the end of month $t$ and that of month $t+1$. Each day contains $m$ intraday observations. $S_{t+\frac{i}{N}, j+1}$ and $S_{t+\frac{i}{N}, j}$ are the spot prices observed on day $t+\frac{i}{N}$ at times $j+1$ and $j$, respectively. The last term to the right of the equality sign simply reflects the effect of overnight returns. In particular, it captures the impact of the return from the end of the previous day to the opening of the following day.

Option-Implied Moments Recent studies document the information content of optionimplied moments, e.g. Jiang \& Tian (2005), Prokopczuk \& Wese Simen (2014), and Kourtis et al. (2016), for realized variance. We exploit the theoretical results of Bakshi et al. (2003) to construct the risk-neutral (i) variance $\left(V A R^{B K M}\right)$, (ii) skewness $\left(S K E W^{B K M}\right)$, and (iii) excess kurtosis $\left(E X K U R T^{B K M}\right)$ :

$$
\begin{aligned}
V A R^{B K M} & =\frac{e^{r \tau} V-\mu^{2}}{\tau}, \\
S K E W^{B K M} & =\frac{e^{r \tau} W-3 \mu e^{r \tau} V+2 \mu^{3}}{\left[e^{r \tau} V-\mu^{2}\right]^{3 / 2}}, \\
E X K U R T^{B K M} & =\frac{e^{r \tau} X-4 \mu e^{r \tau} W+6 e^{r \tau} \mu^{2} V-3 \mu^{4}}{\left[e^{r \tau} V-\mu^{2}\right]^{2}}-3,
\end{aligned}
$$


where $r$ denotes the continuously compounded (annualized) interest rate for the period from $t$ to $t+\tau$. We use the Ivy curve from OptionMetrics to proxy for the interest rate. Essentially, this curve is based on London Interbank Offered Rate (LIBOR) and Eurodollar futures. ${ }^{2} \tau$ indicates the time to expiration of each option, expressed as a fraction of a year. Note that all variables are contemporaneously observed. In the expressions above $V, W, X$, and $\mu$ are defined as follows:

$$
\begin{aligned}
V & =\int_{K=0}^{S} \frac{2\left(1+\log \left[\frac{S}{K}\right]\right)}{K^{2}} P(K) d K+\int_{K=S}^{\infty} \frac{2\left(1-\log \left[\frac{K}{S}\right]\right)}{K^{2}} C(K) d K \\
W & =\int_{K=S}^{\infty} \frac{6 \log \left[\frac{K}{S}\right]-3\left(\log \left[\frac{K}{S}\right]\right)^{2}}{K^{2}} C(K) d K-\int_{K=0}^{S} \frac{6 \log \left[\frac{S}{K}\right]+3\left(\log \left[\frac{S}{K}\right]\right)^{2}}{K^{2}} P(K) d K, \\
X & =\int_{K=S}^{\infty} \frac{12\left(\log \left[\frac{K}{S}\right]\right)^{2}+4\left(\log \left[\frac{K}{S}\right]\right)^{3}}{K^{2}} C(K) d K+\int_{K=0}^{S} \frac{12\left(\log \left[\frac{S}{K}\right]\right)^{2}+4\left(\log \left[\frac{S}{K}\right]\right)^{3}}{K^{2}} P(K) d K, \\
\mu & =e^{r \tau}-1-\frac{e^{r \tau}}{2} V-\frac{e^{r \tau}}{6} W-\frac{e^{r \tau}}{24} X
\end{aligned}
$$

where $K$ and $S$ are the strike and spot prices, respectively. $C(K)$ and $P(K)$ denote the call and put prices of strike $K$, respectively. All other variables are as previously defined.

At the end of each calendar month, we use the OptionMetrics database to extract the standardized options data of 1-month maturity, the contemporaneous spot price, and the interest rate of corresponding maturity. We retain only out-of-the-money option prices. It is worth pointing out that the integrals in the formulas above implicitly assume the existence of a wide range of strike prices. Alas, this is not perfectly true in the market. Thus, we follow Chang et al. (2012) by computing a fine grid of 1,000 equidistant interpolated moneyness levels, i.e. $K / S$, ranging from $1 \%$ to $300 \%$. For each moneyness level on that grid, we interpolate the implied volatility using a spline interpolation method. For moneyness levels outside of the moneyness range observed in the market, we extrapolate the implied volatilities

\footnotetext{
${ }^{2}$ We use this interest rate curve to be consistent with the empirical literature on option prices (e.g., Bali \& Hovakimian, 2009; McGee \& McGroarty, 2017). Obviously, one may wonder if our main results hold if we substitute the OptionMetrics curve with the term-structure of Treasury rates. The effect on our main findings is negligible. The intuition behind this result is that most of our analysis focuses on options of short time to maturity. Because the interest rate is always multiplied by the time to maturity, we find that the interest rate proxy has very little impact on our results.
} 
(Jiang \& Tian, 2005). In practice, this means that if a moneyness level is lower (higher) than the lowest (highest) moneyness level available in the market, we simply use the implied volatility corresponding to the lowest (highest) level of moneyness available in the market. Next, we plug the implied volatilities into the Black \& Scholes (1973) option pricing model to obtain the corresponding out-of-the-money option prices. Finally, we follow Bali et al. (2017) by using a trapezoidal rule to approximate the integrals that appear in the formulas above and obtain the risk-neutral moments of 1-month maturity.

Variance Risk Premium The variance risk premium is defined as the difference between the risk-neutral and physical expectations of variance:

$$
V R P_{t}=E_{t}^{\mathbb{Q}}\left(\sigma_{t+1}^{2}\right)-E_{t}^{\mathbb{P}}\left(\sigma_{t+1}^{2}\right)
$$

where $E_{t}(\cdot)$ is the expectation operator conditional on the information available at time $t$. The superscripts $\mathbb{Q}$ and $\mathbb{P}$ indicate that the expectation is computed under the risk-neutral and physical measures, respectively. In order to proxy for the risk-neutral expectation of variance, we use $V A R^{B K M}$. This choice is motivated by Du \& Kapadia (2012) who show that the risk-neutral variance of Bakshi et al. (2003) is robust to jumps.

While the expression above clearly defines the variance risk premium, it is of very little practical use. The reason for this is that it involves the physical expectation of future variance, which is not directly observable. Therefore, we follow the lead of Bollerslev et al. (2009) and Driessen et al. (2013) in positing a simple random walk model for the future variance under the physical measure. That is, we assume that the expectation of the future variance under the physical measure equals its most recent realization. Thus, we can compute the $V R P$ as follows:

$$
V R P_{t}=V A R_{t}^{B K M}-R V_{t}
$$


Note that all variables are annualized and observed at the end of each calendar month.

Correlation Risk Premium Driessen et al. (2013) establish the predictive power of the correlation risk premium for future aggregate stock returns. The authors observe that the equity index is a portfolio of individual equities (Driessen et al., 2009). An upshot of this is that the variance of the market index return is equal to the weighted average variance of individual stocks and covariance terms. Assuming further that the pairwise correlation between different stocks is the same for all stocks, they are able to derive the following formula:

$$
I C_{t}=\frac{E_{t}^{\mathbb{Q}}\left[\int_{t}^{t+\tau} \sigma_{\Psi, s}^{2} d s\right]-\sum_{\psi=1}^{\Theta} \omega_{\psi}^{2} E_{t}^{\mathbb{Q}}\left[\int_{t}^{t+\tau} \sigma_{\psi, s}^{2} d s\right]}{\sum_{\psi=1}^{\Theta} \sum_{\chi \neq \psi} \omega_{\psi} \omega_{\chi} \sqrt{E_{t}^{\mathbb{Q}}\left[\int_{t}^{t+\tau} \sigma_{\psi, s}^{2} d s\right]} \sqrt{E_{t}^{\mathbb{Q}}\left[\int_{t}^{t+\tau} \sigma_{\chi, s}^{2} d s\right]}}
$$

where $I C_{t}$ is the implied correlation at time $t . \Theta$ denotes the number of stocks in the stock market. $E_{t}^{\mathbb{Q}}\left[\int_{t}^{t+\tau} \sigma_{\Psi, s}^{2} d s\right]$ and $E_{t}^{\mathbb{Q}}\left[\int_{t}^{t+\tau} \sigma_{\psi, s}^{2} d s\right]$ are the risk-neutral expected variance of the index $(\Psi)$ and of the individual stock $(\psi)$, respectively. As before, we proxy these expectations with the risk-neutral variance of Bakshi et al. (2003). $w_{\psi}$ and $w_{\chi}$ are the weights of stocks $\psi$ and $\chi$ in the market index $\Psi$, respectively.

The intuition developed above also holds under the physical measure, thus yielding the following formula for the realized correlation at time $t$ :

$$
R C_{t}=\frac{E_{t}^{\mathbb{P}}\left[\int_{t}^{t+\tau} \sigma_{\Psi, s}^{2} d s\right]-\sum_{\psi=1}^{\Theta} \omega_{\psi}^{2} E_{t}^{\mathbb{P}}\left[\int_{t}^{t+\tau} \sigma_{\psi, s}^{2} d s\right]}{\sum_{\psi=1}^{\Theta} \sum_{\chi \neq \psi} \omega_{\psi} \omega_{\chi} \sqrt{E_{t}^{\mathbb{P}}\left[\int_{t}^{t+\tau} \sigma_{\psi, s}^{2} d s\right]} \sqrt{E_{t}^{\mathbb{P}}\left[\int_{t}^{t+\tau} \sigma_{\chi, s}^{2} d s\right]}}
$$

where $R C_{t}$ is the realized correlation at time $t$. All other variables are as previously defined. As before, we use the historical variance computed over the most recent period to proxy for the physical expectation of the future variance.

The $C R P$ at time $t$ is then defined as the difference between the risk-neutral and physical 
expectations of future correlation, yielding the following result:

$$
C R P_{t}=I C_{t}-R C_{t}
$$

To obtain this variable, we use standardized options (of time to maturity of one month) on the S\&P 500 index as well as options data on all constituents of the index. All options are observed at the end of each calendar month.

Implied Volatility Smirk Measure Xing et al. (2010) document the predictive power of the implied volatility smirk. ${ }^{3}$ Our construction of this variable broadly mirrors theirs. At the end of each calendar month, we retain all S\&P 500 index options with positive open interest and a time to maturity between 10 and 60 days. We discard all option prices with a midquote price below $\$ 0.125$. We also purge all options with implied volatility outside of the interval $[3 \% ; 200 \%]$. We define the out-of-the-money put options as the put options with a moneyness level between 0.8 and 0.95 . Note that by moneyness level, we understand the ratio of the strike price over the stock price, i.e. $K / S$. Relatedly, we define at-the-money call options as call options with a moneyness level between 0.95 and 1.05 . The smirk measure is simply computed as follows:

$$
S M I R K_{t}=V O L_{t}^{O T M P}-V O L_{t}^{A T M C}
$$

where $S M I R K_{t}$ is the smirk measure at time $t$. VOL $L_{t}^{O T M P}$ denotes the implied volatility of out-of-the-money puts. To be more precise, this is the volume-weighted average of the implied volatilities of all out-of-the-money put options. $V O L_{t}^{A T M C}$ refers to the volume-weighted

\footnotetext{
${ }^{3}$ Xing et al. (2010) analyze the predictive ability of the implied volatility smirk in the cross-section of stock returns. Motivated by the intertemporal capital asset pricing model (ICAPM) of Merton (1973), if SMIRK is priced in the cross-section, it also has to predict the investment opportunity set in the time series (Maio \& Santa-Clara, 2012).
} 
average of all implied volatilities of at-the-money calls at time $t$.

Risk-Neutral Riskiness Leiss \& Nax (2018) apply the result of Foster \& Hart (2009) to the risk-neutral density of the $\mathrm{S} \& \mathrm{P} 500$ index to derive an option-implied riskiness measure. We follow Leiss \& Nax (2018) and first obtain the risk-neutral density of the S\&P 500 using the approach of Figlewski (2010). That is, for the center of the distribution, i.e. the moneyness range observed in the market, we interpolate the implied volatilities using a 4th order spline with one knot at-the-money, computing the density using the corresponding Black \& Scholes (1973) option prices. Finally, we parameterize the distributions of the left and right tails by separately fitting Generalized Extreme Value (GEV) distributions. Using the obtained distribution, we compute the risk-neutral Foster-Hart (FH) riskiness measure by solving the following equation:

$$
\int_{S_{T}=0}^{\infty} \log \left(1+\frac{S_{T}-S_{0}}{S_{0}} F H\right) f\left(S_{T}\right) d S_{T}=0,
$$

where $S_{T}$ and $S_{0}$ are the stock prices at expiration and $t=0$, respectively. $f\left(S_{T}\right)$ is the risk-neutral density at $S_{T}$. We numerically compute the integral using a trapezoidal rule and repeat this procedure on every trading day. Leiss \& Nax (2018) remark that in some cases, Equation (16) does not have a solution, $F H \in(0,1)$, in which case they set $F H$ to 1 if the option-implied expected return $\left(\int_{S_{T}=0}^{\infty} \frac{S_{T}-S_{0}}{S_{0}} f\left(S_{T}\right) d S_{T}\right)$ is positive. If the option-implied return is negative and Equation (16) does not have a solution, we set $F H$ to 0 . FH may be interpreted as the fraction of wealth that can be invested in an asset so that no-bankruptcy is guaranteed. For this measure, we use data on traded option prices for all options on the S\&P 500 for maturities between 10 and 50 days, each day picking the time to maturity 
closest to 30 days. $^{4}$ For the empirical tests, we follow Leiss \& Nax (2018) and use a 21-day moving average of $F H$ instead of the raw measure.

Generalized Measure of Riskiness Based on both Foster \& Hart (2009) and Aumann \& Serrano (2008), Bali et al. (2011) introduce a generalized measure of riskiness $(G M R)$. We obtain $G M R$ by solving the equation:

$$
\int_{K=0}^{S} f_{R}(K) P(K) d K+\int_{K=S}^{\infty} f_{R}(K) C(K) d K-\frac{r \tau}{1+r \tau} \frac{1}{G M R}=0
$$

with

$$
f_{R}(K)=\frac{(1-\delta)}{S^{2} G M R^{2}}\left(1+\frac{K / S-1}{G M R}\right)^{\delta-2}
$$

Following Bali et al. (2011), we set $\delta=-2$. All other variables are as previously defined. We compute the integrals for each trading day as described in the paragraph "Option-Implied Moments" using the standardized options with time to maturity of one month.

\section{Main Results}

Before discussing our main findings, it is instructive to look at the summary statistics reported in Table I. We can observe a positive market risk premium of around $6 \%$ p.a. The risk premium exhibits a standard deviation of around $16 \%$ p.a. We also notice that the sample moments of the $V R P$ and the $C R P$ are consistent with those reported in previous works (Driessen et al., 2009, 2013). In particular, we can see that although positive on average, the $V R P$ is negatively skewed and prone to extreme movements as indicated by its high kurtosis, suggesting a sign-switching behavior. This observation could carry important

\footnotetext{
${ }^{4}$ For most measures in this study, we rely on the standardized options, provided by OptionMetrics. However, these are not suitable to obtain the entire risk-neutral density because they do not provide observations for deep out-of-the-money options which are necessary to accurately parametrize the GEV distributions.
} 
implications for the predictive ability of this variable. We shall return to this point later.

The table also reports the $\mathrm{AR}(1)$ coefficient of each variable. We notice that the autoregressive coefficient of these variables is typically lower than that of the valuation ratios such as the (log) dividend to price ratio routinely analyzed in empirical works, e.g. Goyal \& Welch (2003). This suggests that our analysis does not suffer from the statistical issues that affect these earlier works. We can also see that the $\mathrm{AR}(1)$ coefficient of the realized variance is much higher than that of the market risk premium, likely indicating that there might be a stronger evidence of predictability in the realized variance series than in the market excess returns.

Table II presents the sample correlation coefficients among all the predictive variables. While most variables are only weakly correlated, there is a high correlation between $S K E W^{B K M}$ and $E X K U R T^{B K M}(-0.92)$. This suggests that these variables contain very similar information.

\section{III.A Return Predictability}

In-Sample Analysis We start by assessing the in-sample predictability of the equity risk premium. To do so, we estimate the standard regression model of the month-ahead excess return on a constant and the predictive variable(s):

$$
E R_{t+1}=\beta_{0}+\beta_{1} X_{t}+\epsilon_{t+1}
$$

where $E R_{t+1}$ is the excess return on the market realized at the end of month $t+1$. $\beta_{0}$ and $\beta_{1}$ are the intercept and slope parameters, respectively. $X_{t}$ represents the forecasting variable(s) observed at the end of month $t$. Finally, $\epsilon_{t+1}$ is the regression error term at $t+1$.

Table III summarizes the results for each predictive variable. The regression model enables us to ascertain whether the equity risk premium is time-varying or constant. Under 
the null hypothesis that the future excess return cannot be predicted using $X_{t}$, we would expect that $\beta_{1}=0$. As a result, the expected market excess return would simply be constant. One implication of this is that the best estimate of the future excess return is simply its recursive mean. If there is evidence of predictability, we would expect to see that the slope loading is statistically significant. To avoid a small-sample bias (Stambaugh, 1999) and serial correlation in the error terms (Richardson \& Stock, 1989), we base our statistical inference on the bootstrapped distribution obtained by implementing the framework of Rapach \& Wohar (2006). ${ }^{5}$

We can see that the $C R P, G M R, S M I R K$, and $V R P$ are statistically significant predictors in the univariate regressions. This is documented by their $t$-statistics of 2.76 , $2.09,-2.06$, and 4.26 , respectively. The positive and significant slope estimate related to the $V R P$ confirms and updates, using a more recent sample period, the result of Bollerslev et al. (2009). It is also consistent with the authors' intuition that the $V R P$ encodes information about time-variations in economic uncertainty. Note also that if, as argued by Driessen et al. (2013), $C R P$ accounts for most of the $V R P$, then one would expect that $C R P$ predicts future excess returns with a positive sign as we find in the data, since it has been documented that the VRP predicts the market excess return (Bollerslev et al., 2009).

The result that $C R P$ predicts future returns is consistent with that in Driessen et al. (2009, 2013). There is a strong relationship between correlations and returns. It seems that correlations between stocks are time-varying and that correlations increase when returns are

\footnotetext{
${ }^{5}$ We estimate the process under the null hypothesis of no predictability, i.e. $E R_{t}=a_{0}+\epsilon_{1, t}$ and $X_{t}=b_{0}+b_{1} X_{t-1}+\epsilon_{2, t}$, where $a_{0}, b_{0}$, and $b_{1}$ are the regression coefficients and $\epsilon_{1, t}$ and $\epsilon_{2, t}$ are the error terms, respectively. We then form a series of error terms and set up our pseudo sample. For the pseudo sample, we compute the in-sample and out-of-sample statistics. Finally, we repeat this procedure 1,000 times. In the case of multiple regressions, we adjust the procedure by taking the multiple variables into account and, in-sample, by using the $F$-statistic rather than the individual $t$-statistic.
} 
low. ${ }^{6,7}$ Moreover, the authors document a strong predictive power of $I C$ for future returns, supported by a correlation of 0.24 between $I C$ and $V R P$, shown in Table II. ${ }^{8}$ Pollet \& Wilson (2010) provide evidence for the predictive power of (average) realized correlations for stock returns at a quarterly horizon.

The result of $G M R$ for predicting future market returns confirms the findings of Bali et al. (2015). The authors find that $G M R$ acts as a significant positive in-sample predictor of future aggregate market returns. The positive sign is consistent with the interpretation of $G M R$ as a fundamental measure of risk: higher riskiness is associated with higher aggregate excess returns in the future.

The finding that $S M I R K$ predicts future returns with a negative sign extends the results of Xing et al. (2010) to the time series of the market excess return. The intuition behind this result is simple. An increase in $S M I R K$ implies a stronger demand for out-of-the-money put options. This increased demand signals that investors are actively purchasing insurance against expected declines in the stock index. The negative slope estimate of $S M I R K$ is consistent with this intuition.

It is also worth comparing the predictive power of individual variables. A cursory look at the in-sample $R^{2}$ reveals that $V R P$ has the highest predictive power for future excess returns $\left(R^{2}=7.47 \%\right)$. The second most powerful predictor is the $C R P$, with an $R^{2}$ of $3.28 \%$. While the slope estimate on the $V R P$ is similar to that documented by Bollerslev

\footnotetext{
${ }^{6}$ They show that an increase in market correlations has two main effects. First, diversification possibilities are lower, thus, investors face limitations in their portfolio formations and suffering from a welfare reduction. Second, there is a rise in market volatility. One implication is that index options become relatively expensive compared to individual options. They represent a hedge against changes in market correlations, thus, also against losses due to diversification limitations.

${ }^{7}$ The use of $C R P$ (and of $I C$ and $R C$ ) can be theoretically motivated by the ICAPM of Merton (1973). It directly affects future investment opportunities, i.e. investors' future diversification benefits as well as the market variance. Moreover, Driessen et al. (2013) argue that CRP appears to drive the volatility of dividend growth, and also the volatility of dividend growth volatility, consistent with the argument of Bollerslev et al. (2009) for $V R P$. One implication is that $C R P$ matters for both return as well as variance predictability.

${ }^{8}$ Driessen et al. $(2009,2013)$ document that $I C$ strictly exceeds $R C$, indicating the existence of a large $C R P$. Our data support these findings. We observe a mean $I C(R C)$ of $41.66 \%(32.25 \%)$, generating a mean $C R P$ of $9.41 \%$.
} 
et al. (2009), it is worth noticing that the predictive power we document at the monthly horizon is much higher, indicating that, if anything, the predictive ability of the $V R P$ is much stronger in the more recent sample period.

It is worthwhile to analyze the performance of individual variables over time. Figure 1 plots the in-sample cumulative differences in squared forecast errors (CDSFE). ${ }^{9}$ We observe a similar (in-sample) performance in the case of the $C R P$ and $V R P$, indicated by a sharp increase during the global financial crisis in 2008/2009, and a steady rise during the post crisis period. The findings suggest the outperformance of the unrestricted model to the restricted model, particularly in times of distress. It seems that investors can exploit the information content of both variables in times of high risk-aversion.

In the case of $E X K U R T^{B K M}$ and $S K E W^{B K M}$, we find an increase in performance during the global financial crisis; however, afterwards there is a steady decline, suggesting the superior performance of the restricted model. Both variables appear to have substantial predictive power, particularly in crises. The CDFSE plot for $G M R$ indicates that most of the predictive power stems from economic downturns.

SMIRK shows the strongest increase in the CDSFE plot during the global financial crisis, indicating that investors look for a hedge against a further market downturn, by buying put options. Finally, in the case of $V A R^{B K M}$, we see no strong fluctuations in its CDSFE, suggesting a similar performance of both the unrestricted and restricted model. Generally, we also find a strong increase in the performance after the dot-com bubble in 2001. This is true for all variables, except $S M I R K$.

To analyze the joint predictive ability of different variables, we perform three multiple regressions. Due to the high correlation between $S K E W^{B K M}$ and $E X K U R T^{B K M}$, we run

\footnotetext{
${ }^{9}$ Please note that whenever there is a rise of the in-sample (or out-of-sample) performance, the unrestricted model outperforms the restricted model, and vice versa. In this case, a variable provides a better forecast than the benchmark model.
} 
the regressions also once without the first and once without the second variable. ${ }^{10}$ In all

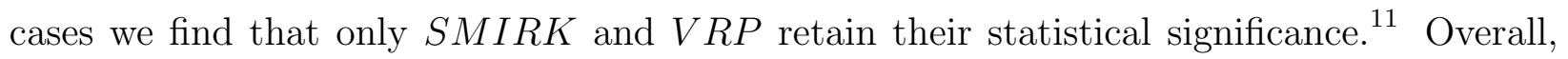
the adjusted $R^{2}$ increases to $8.81 \%, 8.95 \%$, and $8.59 \%$ in the first, second, and third case, respectively.

Out-of-Sample Results We now turn our focus to the out-of-sample evidence of return predictability. We use an initial training window of 5 years to first estimate the forecasting model presented in Equation (19). Equipped with the parameter estimates and the most recent observation of the forecasting variable in the training window, we are able to generate the first excess return forecast. The following month, we expand the training window by one observation month and re-estimate the forecasting model. With the new parameter estimates, we forecast the market excess return for the next month. We proceed analogously for all months, except the last month of our sample period.

In order to assess the out-of-sample performance of different models, we follow Campbell \& Thompson (2008) and define the out-of-sample $R^{2}\left(R_{\text {oos }}^{2}\right)$ as follows:

$$
R_{\text {oos }}^{2}=1-\frac{M S E_{u}}{M S E_{r}}
$$

where $M S E_{u}$ and $M S E_{r}$ are the mean squared errors of the unrestricted and restricted models, respectively. The unrestricted model is based on Equation (19). The restricted model imposes the null hypothesis that returns are unpredictable, i.e. $\beta_{1}=0$. Thus the $R_{\text {oos }}^{2}$ sheds light on the question: How large an improvement in forecast accuracy can one achieve by accounting for the predictive power of variable $X_{t}$ ? The higher the $R_{\text {oos }}^{2}$ the better. A

\footnotetext{
${ }^{10}$ We present the results of the multiple regressions only for return predictability. In the case of realized variance predictability, we skip these regressions due to multicollinearity.

${ }^{11}$ The $C R P$ does not retain its statistical significance in the multiple regressions. It seems that other variables, mainly the $V R P$, capture its information. In-sample multiple regressions have no explanatory power for out-of-sample predictability. For further details, wee also refer to the forthcoming out-of-sample analysis.
} 
variable has notable predictive power if it exhibits a positive and significant $R_{\text {oos }}^{2}$, indicating an overall outperformance of the predictive variable.

In order to gauge whether the potential improvement is statistically significant, we compute the $M S E-F$ statistic of McCracken (2007):

$$
M S E-F=H \times\left(\frac{M S E_{r}-M S E_{u}}{M S E_{u}}\right)
$$

where $H$ denotes the number of out-of-sample forecasts. All other variables are as previously defined. Briefly, the null hypothesis is that the restricted model performs at most as well as the unrestricted model, i.e. $M S E_{r} \leq M S E_{u}$. The alternative is that the unrestricted model provides smaller forecast errors than the restricted model. As can be seen from the last row of Table III, only $C R P$ and $V R P$ yield statistically significant improvements in the out-of-sample performance relative to the simple recursive mean. This result is noteworthy given that Goyal \& Welch (2003) argue that the recursive mean is a tough benchmark to beat. Overall, these results suggest that the $C R P$ and the $V R P$ contain important information about next-month's market excess returns both in- and out-of-sample. In contrast, the multiple regressions do not improve the predictive power out-of-sample. In Figure 1, we observe a similar development of the out-of-sample performances as in-sample, except for $V A R^{B K M}$, showing a sharp drop during the global financial crisis, indicating a superior performance of the restricted model. It seems that investors have to rely on the historical mean rather than on $V A R^{B K M}$ in times of distress.

\section{III.B Variance Predictability}

We now turn our attention to the predictability of the realized variance. In particular, we ask the question: Can any of the forecasting variables be used to predict next-month's realized variance? 
In-Sample Using all the sample information, we estimate the following regression model:

$$
R V_{t+1}=\gamma_{0}+\gamma_{1} X_{t}+\gamma_{2} R V_{t}+\epsilon_{t+1},
$$

where $\gamma_{0}, \gamma_{1}$, and $\gamma_{2}$ are the intercept and slope parameters, respectively. All other variables are as previously defined. We include the lag of realized variance, because realized variance is a strongly persistent process, indicated by its $\operatorname{AR}(1)$ coefficient of 0.63 , shown in Table I. ${ }^{12}$ To account for the persistence, we use a fitted $\mathrm{AR}(1)$ process as naive benchmark rather than the historical mean variance. ${ }^{13}$

Table IV summarizes the results of the in-sample analysis. We notice that the variables have predictive power for future realized variance, as evidenced by their statistically significant $R^{2} s{ }^{14}$ This is true for all variables, except $F H$ and $G M R$. The $R^{2} s$ range from $40.80 \%$ to $43.03 \%$. These results are interesting for several reasons. First, they indicate that the predictability of realized variance is much stronger than that of excess returns. Second, they reveal that $C R P, S M I R K$, and $V R P$ are able to predict (in-sample) not only next-month's market excess return (see Table III) but also realized variance. Third, the risk-neutral variables of Bakshi et al. (2003) that do not predict future excess returns matter for realized variance forecasting. For instance, $E X K U R T^{B K M}$ predicts next-month's realized variance with a predictive power equal to $41.60 \%$. GMR appears to predict only market returns, whereas $F H$ predicts neither market returns nor realized variance. A likely cause for the rather poor performance of the two measures is that both variables exhibit clear breakpoints, especially around the financial crisis (see the time-series of these variables for example in Figure 1 of Bali et al. (2015) as well as Figure 1 of Leiss \& Nax (2018)).

\footnotetext{
${ }^{12}$ Since realized variance is strongly persistent, future realized variance is primarily predictable by its current value. Ignoring the lag of realized variance allows the other lagged variables to partially capture this persistence. In particular $V A R^{B K M}$ and $R V$ are highly correlated. We refer to this point later in Table IV.

${ }^{13}$ In Section $V . C$, we use the historical mean variance as naive benchmark and show the results.

${ }^{14}$ Although $C R P$ has a $t$-statistic of -1.59 , this variable generates a statistically significant improvement in the in-sample $R^{2}$ of $40.80 \%$. We also refer to Section V.C.
} 
An implication of this result is that when assessing the information content of a predictive variable, it is advisable to investigate whether it predicts not only excess returns but also realized variance. We observe that $V A R^{B K M}$ and $V R P$ have similar $t$-statistics and $R^{2} s$, which is not surprising due to the construction of $V R P$ and the used regression model in Equation (22).

Figure 2 shows the CDSFE for all individual variables predicting the next month's realized variance. There is a similar pattern for the variables. We observe a strong increase in their performance during the global financial crisis in $2008 / 2009$, indicating the outperformance of the unrestricted model to the restricted model. It seems that investors can exploit the information content of the variables, particularly in times of high variance.

Out-of-Sample We use the first 5 years of observations to initially estimate the model parameters (see Equation (22)). Having done this, we then make a forecast for the following month. We expand the training window by one observation month and repeat all steps. This procedure mirrors that used for the return predictability analysis with the only difference that we assume a fitted $\mathrm{AR}(1)$ process as naive benchmark and that we forecast realized variance rather than the market excess return. The last row of Table IV shows the $R_{o o s}^{2} s$. All variables that predict realized variance in-sample are also good predictors out-of-sample. The $R_{\text {oos }}^{2} s$ range from $2.40 \%$ for $S K E W^{B K M}$ to $3.89 \%$ for $S M I R K$. In Figure 2, we observe a similar pattern as in-sample. In particular in times of distress, investors should rely on the information content of the predictive variables rather than on the forecast of a fitted $\mathrm{AR}(1)$ model.

\section{III.C Portfolio Choice Implications}

We now study the portfolio choice implications of the predictability results reported earlier. To do this, we consider an investor with mean-variance preferences. The agent 
allocates a fraction $\omega_{t}$ of her wealth to the risky portfolio and the remainder, i.e. $1-\omega_{t}$, to the risk-free asset. The agent's objective function is:

$$
\max _{w_{t}} E_{t}^{\mathbb{P}}\left(r_{p, t+1}-\frac{\gamma}{2} \sigma_{p, t+1}^{2}\right)
$$

where $E_{t}^{\mathbb{P}}(\cdot)$ is the physical expectation operator. $r_{p, t+1}$ is the next-period's (simple) return on the investor's portfolio. $\gamma$ is the coefficient of relative risk-aversion. $\sigma_{p, t+1}^{2}$ is the conditional variance of the portfolio from $t$ to $t+1$. This return is the weighted average of the (simple) return on the risky stock and on the risk-free asset. Because our earlier analysis focuses on log-returns rather than simple returns, we use a second-order Taylor expansion to express the simple return as a function of the log-return and realized variance. ${ }^{15}$ Thus, we can express the objective function as follows:

$$
\max _{w_{t}} E_{t}\left(R_{p, t+1}-\frac{\gamma-1}{2} \sigma_{p, t+1}^{2}\right)
$$

where $R_{p, t+1}$ is the log-return on the portfolio and all other variables are as previously defined.

Using the first-order condition, it is straightforward to derive the optimal weight invested in the risky asset (Jordan et al., 2014):

$$
\omega_{t}=\frac{E_{t}\left(E R_{t+1}+\frac{1}{2} R V_{t+1}\right)}{\gamma E_{t}\left(R V_{t+1}\right)}=\frac{E_{t}\left(E R_{t+1}\right)}{\gamma E_{t}\left(R V_{t+1}\right)}+\frac{1}{2 \gamma} .
$$

The expression above shows that the optimal allocation to the risky asset depends on the expected excess return, the risk-aversion parameter, and the expected realized variance. One implication of this expression is that, holding everything else constant, the allocation to the

\footnotetext{
${ }^{15}$ More precisely, the approximation yields the following relationship:

$$
R_{t} \approx r_{t}-\frac{1}{2} R V_{t}
$$

where $R_{t}, r_{t}$, and $R V_{t}$ are the log-return, simple return, and realized variance at time $t$, respectively.
} 
risky stock rises with expected returns. In other words, if realized variance is unpredictable and a forecasting variable $X_{t}$ positively (negatively) predicts excess returns, then the agent would invest more (less) in the risky stock as $X_{t}$ increases. In contrast, if a variable $X_{t}$ positively predicts future variance (and not returns), then the share of wealth invested in the risky stock decreases with the variable $X_{t}$.

Note that the preceding discussion focuses only on the predictability of either returns or variance and does not explore the case where both moments are predictable by the same variable. The share of the position in the stock will be determined by two (potentially offsetting) forces, one that increases with the expected excess return and the other that decreases with the expected realized variance.

In light of the preceding discussion, we find it interesting to distinguish between three cases. The first one deals with the case where only excess returns might be predictable. The second case allows for the predictability of realized variance alone. The third case deals with the possibility that both excess returns and realized variance are predictable by the same variable $X_{t}{ }^{16}$

For a given case $(\xi)$ and each calendar month of our out-of-sample window, we compute the weight $\omega_{t}$ and also the realized return of the portfolio. We impose the restriction that whenever the forecast of the market excess return or of the realized variance (or of both) in Equation (25) equals zero, we set the portfolio weight equal to $1 /(2 \gamma)$. Further, following Campbell \& Thompson (2008) and Jordan et al. (2017), we impose the restriction that $\omega_{t}$ is bounded from below by 0 and from above by 1.5. Economically, the lower bound implies that the agent does not short-sell the risky asset. The upper bound prevents the agent from taking on excessive leverage. At the end of the sample period, we compute the certainty

\footnotetext{
${ }^{16}$ To be consistent with Section III.B, we predict realized variance by the variable $X_{t}$ and the lag of realized variance.
} 
equivalent return as follows:

$$
C E R^{(\xi)}=\bar{r}_{p}-\frac{\gamma}{2} \sigma_{p}^{2}
$$

where $C E R^{(\xi)}$ is the certainty equivalent return associated with strategy $\xi$. This number is expressed in percent per annum. $\bar{r}_{p}$ is the average (annualized) return on the portfolio. $\sigma_{p}^{2}$ is the variance of the portfolio returns.

Our approach consists in computing the utility gain $\left(\Delta C E R^{(\xi)}\right)$, the difference between $C E R^{(\xi)}$ and the certainty equivalent return of the naive strategy that assumes that the first two moments are unpredictable, and thus relies on simple historical averages. We do this for each of the three scenarios.

We also compute the Sharpe Ratio $(S R)$ of each strategy $\xi$ :

$$
S R^{(\xi)}=\frac{\bar{R}_{p}-r f}{\sigma_{p}^{2}},
$$

where $\bar{R}_{p}$ is the average log-return on the portfolio. Similar to the certainty equivalent return analysis, we compute the improvement in $S R$ by taking the difference between $S R^{(\xi)}$ and the $S R$ linked to the naive strategy that assumes that the market excess return and realized variance are unpredictable. We use an approach suggested by Jobson \& Korkie (1981), and after taking into account the correction suggested by Memmel (2003), we test whether the improvement is statistically significant.

Table $\mathrm{V}$ reports our results for different values of risk-aversion. We can see that statistical evidence of excess return predictability does not necessarily imply important economic gains. For instance, while the $V R P$ predicts both excess returns and realized variance, a timing strategy relying on this variable would have underperformed the naive strategy. One possible explanation for this result is the following. Shortly before the crisis 
period, the variance risk premium is high (since the historical variance is low). Because the $V R P$ predicts future returns with a positive sign, this result implies that an agent should hold more (rather than less) stocks. As a result of this increased position, the strategy incurs more severe losses as the economy slides into recession. Similarly, as the economy recovers, the variance risk premium is low, implying that the agent should hold a small position in the stock. Because of this, the agent misses out on the rally in the market. Further, it seems that, though $V R P$ predicts both returns and variance individually with a positive sign, the joint predictability is associated with large variance, thus generating negative certainty equivalent returns. ${ }^{17}$

In contrast, one can see that relative to an agent with risk-aversion $\gamma=3$ who assumes that the market excess return and the realized variance are unpredictable, the agent who exploits the information content of the $C R P$, would improve her utility by $5.03 \%$ p.a. The finding is consistent with Driessen et al. (2009, 2013) who document that index options represent a hedge against changes in market correlations, and also against losses due to diversification limitations.

Our results are in line with those of Fleming et al. (2001), who show that volatility timing leads to notable utility gains for short-horizon investors. The positive economic value generated by the $C R P$ is consistent with the work of Buss et al. (2018), who document a positive CER for the market timing strategy based on the $C R P$. Overall, our findings suggest that investors might earn larger utility gains when taking the predictability of both excess returns and realized variance into account.

Table A1 of the Online Appendix shows the portfolio choice implications taking into account turnover and transaction costs. Following DeMiguel et al. (2009), we define the

\footnotetext{
${ }^{17}$ We refer to Section $I V . B$ for further details.
} 
turnover for strategy $\xi$ as the average sum of the absolute values of the trades, i.e.:

$$
\text { Turnover }=\frac{1}{T-H} \sum_{t=1}^{T-H}\left(\left|\omega_{t+1}^{(\xi)}-\omega_{t^{+}}^{(\xi)}\right|\right)
$$

where $T-H$ is the number of out-of-sample observations and $\omega_{t^{+}}^{(\xi)}$ is the portfolio weight before rebalancing at $t+1$. All other variables are as previously defined. For the benchmark strategy, we observe an absolute value of the turnover (Turnover ${ }_{a b s}$ ) of 0.0448 , which can be interpreted as the average percentage of wealth traded in each out-of-sample period. For our three strategies, we report the turnover $\left(\right.$ Turnover $\left._{\text {rel }}^{(\xi)}\right)$ relative to the benchmark case. We notice that all strategies exhibit higher turnovers than the benchmark, indicated by values larger than one.

We follow Balduzzi \& Lynch (1999) and include transaction costs of 50 basis points per transaction proportional to the asset's traded size $\left|\omega_{t+1}^{(\xi)}-\omega_{t^{+}}^{(\xi)}\right|$. Table A1 of the Online Appendix reports the corresponding utility gains and Sharpe Ratios. We observe that transaction costs have an impact on the results; however, the results are qualitatively similar. An agent who relies on the $C R P$ would still improve her utility by $1.38 \%$ p.a.

\section{Further Analyses}

\section{$I V . A \quad$ Sign Restriction}

Campbell \& Thompson (2008) propose imposing two economically motivated restrictions when studying the question of predictability. The authors suggest setting the slope estimate in the out-of-sample analysis equal to zero whenever its sign differs from that of the in-sample analysis. They also suggest setting the out-of-sample forecast equal to zero whenever its negative. Before discussing our findings, it is worth emphasizing that the first constraint is not implementable in real-time. This is because the implementation would 
require the agent to know about the sign of the in-sample slope parameter, i.e. to have information about future data, thus, introducing a look-ahead bias.

The first set of results in Table VI reports the findings when imposing the first restriction. Panel A shows that the main results are similar: the $C R P$ and $V R P$ are the two best option-implied predictors for the market excess return. It is worth noticing that imposing the restriction has very little effect on the $R_{\text {oos }}^{2}$ related to the forecasting variables (see Table III for comparison). This suggests that the sign of the relationship between the forecasting variables $C R P$ and $V R P$ and future excess returns is relatively stable out-of-sample.

We also impose the restriction on the slope of the realized variance forecasting regression. In other words, we set the slope estimate equal to zero, if the sign of the recursively estimated parameter is different from that obtained in-sample. ${ }^{18}$ Overall, we can see from Panel B of Table VI that this restriction has very little impact on our main results.

The second set of results in Table VI reports the findings when imposing the second restriction. Finally, the last entries of each panel show the results when we jointly impose the restrictions (on the sign of the slope and the sign of the return/variance forecast). Summarized, in both cases our main results remain unchanged. ${ }^{19}$ We also repeat our economic value analysis using these economically motivated constraints. Tables VII to IX document that imposing the restriction(s) does (do) not affect our main conclusions on the economic value of the predictive power of both $C R P$ and $V R P$.

\footnotetext{
${ }^{18}$ To be consistent with Section III.B, we impose the restriction for both the variable $X_{t}$ and the lag of realized variance.

${ }^{19}$ Table A2 of the Online Appendix reports the absolute frequency of how often the restrictions are binding. Panel A shows the results for return predictability. We observe that the first restriction is not binding. This is true for all variables, except $F H, G M R$, and $V A R^{B K M}$, indicated by a frequency of 12,8 , and 35. The second restriction is binding more frequently, indicated by frequencies from 7 for $G M R$ to 77 for $V R P$. It seems that the forecast restriction matters more for excess return predictability. Panel $\mathrm{B}$ of Table A2 shows the frequencies in the case of variance predictability. We find that the first (second) restriction is binding only for $C R P, F H$, and $G M R\left(E X K U R T^{B K M}\right)$ with a frequency of 75,76 , and 3 (3). Lagged realized variance appears to be not affected by the (first) restriction(s) at all, indicating the persistence of that variable. The findings reveal that the imposition of economically motivated restrictions matters more for return rather than variance predictability.
} 


\section{$I V . B \quad$ Forecast Combination}

Rapach et al. (2010) suggest the use of forecast combinations. The pooled forecast is the weighted average of all $G$ individual forecasts, where $g=1, \ldots, G$, i.e., $\widehat{E R}_{t+1}^{\text {pool }}=$ $\sum_{g=1}^{G} x_{g, t} \widehat{E R}_{g, t+1}$ and $\widehat{R V}_{t+1}^{\text {pool }}=\sum_{g=1}^{G} x_{g, t} \widehat{R V}_{g, t+1}$, based on Equation (19) and (22), respectively. $x_{g, t}$ is the weight of the individual forecast in the pooled one.

Following the literature, we use three approaches. Table X shows the out-of-sample $R^{2} s$ of (i) the mean forecast combination, where the weight is simply $1 / G$ for $g=1, \ldots, G$, (ii) the median forecast combination, where the pooled forecast is just the median of all individual forecasts, and (iii) the trimmed mean forecast combination, where $x_{g, t}=0$ in the case of the individual forecasts with the smallest and largest value, respectively, and $x_{g, t}=1 /(G-2)$ for the remaining forecasts.

The mean forecast combination exhibits superior performance in the case of return predictability $\left(R_{\text {oos }}^{2}=1.76 \%\right.$ ), whereas the median forecast combination works better in the case of variance predictability $\left(R_{\text {oos }}^{2}=4.12 \%\right) .{ }^{20}$ The findings are interesting for several reasons. First, they support the results of Rapach \& Zhou (2013), who argue that forecast combinations yield more stable forecasts and increase the forecasting performance. Second, the findings show a substantial increase in the magnitude of the $R_{o o s}^{2} s$. In the case of return predictability, the mean forecast combination generates an $R_{\text {oos }}^{2}$ which is substantially larger than for all individual variables, except for $V R P{ }^{21}$ The median forecast combination outperforms all individual variables, predicting realized variance. Third, the findings support our previous conclusion. It seems that individual predictive variables generate notable

\footnotetext{
${ }^{20}$ Since $F H$ and GMR show an overall weak performance, we additionally compute the forecast combinations without these two variables. In that case, the mean forecast combination exhibits a superior performance, indicated by an $R_{\text {oos }}^{2}$ of $3.11 \%$, whereas the median forecast combination generates an $R_{\text {oos }}^{2}$ of $4.83 \%$.

${ }^{21}$ In detail, when using all predictive variables of our sample, the mean forecast combination generates an $R_{\text {oos }}^{2}$ which is similar to all individual variables, except for $V R P$. However, by excluding $F H$ and $G M R$, the mean forecast combination generates an $R_{o o s}^{2}$ which is substantially larger than for all individual variables, except for $V R P$.
} 
variance when predicting excess returns and realized variance, respectively.

Table XI reports the economic value for different values of risk-aversion. Compared with our previous findings, all forecast combinations, in particular the median forecast combination, generate substantial certainty equivalent returns. For $\gamma=3$, an annualized utility gain of $6.73 \%$ (relative to the naive strategy) may be achieved, when both return and variance are predicted by the combined forecast. It seems that forecast combinations rather than individual variables, generate more stable forecasts, thus, leading to significant positive utility gains.

\section{IV.C Predictability of the Sharpe Ratio}

After predicting excess returns and realized variance in isolation, we want to answer the question: What predictive power do the variables have, when predicting excess returns and realized variance jointly? In doing so, we estimate the following regression model:

$$
\frac{E R_{t+1}}{\sqrt{R V_{t+1}}}=\varphi_{0}+\varphi_{1} X_{t}+\epsilon_{t+1}
$$

where $\frac{E R_{t+1}}{\sqrt{R V_{t+1}}}$ is the Sharpe Ratio, and $\varphi_{0}$, and $\varphi_{1}$ are the intercept and slope parameters, respectively. All other variables are as previously defined.

Table XII documents the results for each predictive variable. The regression model (29) enables us to assess whether each variable has predictive power, when predicting excess returns and realized variance jointly. We find that $C R P, G M R, S K E W^{B K M}$, and $V R P$ have predictive power for the future Sharpe Ratios, shown by their statistically significant $t$-statistics of $2.43,1.77,-1.79$, and 2.17. A look at the in-sample $R^{2} s$ reveals that $C R P$ and $V R P$ have the highest (in-sample) predictive power of $2.56 \%$ and $2.04 \%$, respectively.

Further analysis reveals that $C R P$ and $V R P$ also contain important information about the future Sharpe Ratio out-of-sample, indicated by $R_{o o s}^{2} s$ of $2.99 \%$ and $1.54 \%$. 


\section{Additional Analysis}

To use more information when estimating the realized variance, we follow Corsi (2009) and Sévi (2014) and use the heterogenous autoregressive $(H A R)$ model. The $H A R-R V$ model provides a conditional estimate for realized variance that accounts for different trading horizons. Further, in the previous analysis, we examine the total variance risk premium. However, Andersen \& Bondarenko (2010), Andersen et al. (2015), and Feunou et al. (2015) show how to decompose the variance risk premium into downside and upside components. In the following section, we analyze the predictability of both components separately.

We follow Andersen \& Bondarenko (2010) and Andersen et al. (2015) and use the downside and upside model-free implied variance. Following the arguments of Feunou et al. (2015), investors dislike increases in the volatility of the underlying, which is associated with an increase in the probability of severe losses. Investors hedge against these downward movements, thus, we expect that the downside variance risk premium is the main driver of the variance risk premium. Further, to get a better estimate for the physical expectation of variance, we analogously use the downside and upside realized variance.

\section{V.A Variables}

Variance Risk Premium based on HAR-RV Model We define the variance risk premium based on the $H A R-R V$ model $\left(V R P^{H A R}\right)$ as the difference between the risk-neutral variance $\left(V A R^{B K M}\right)$ and the $R V$, estimated on the basis of the $H A R$ model $\left(R V^{H A R}\right)$ :

$$
V R P_{t}^{H A R}=V A R_{t}^{B K M}-R V_{t}^{H A R}
$$


where $V A R_{t}^{B K M}$ is as previously defined. Analogously to Section II.B and using Equation (2), we follow Christoffersen (2012) and define

$$
\begin{aligned}
R V_{D, t+\frac{i}{N}} & \equiv R V_{t+\frac{i}{N}}, \\
R V_{W, t+\frac{i}{N}} & \equiv R V_{\left(t+\frac{i}{N}\right)-4, t+\frac{i}{N}} \\
& =\left[R V_{\left(t+\frac{i}{N}\right)-4}+R V_{\left(t+\frac{i}{N}\right)-3}+R V_{\left(t+\frac{i}{N}\right)-2}+R V_{\left(t+\frac{i}{N}\right)-1}+R V_{t+\frac{i}{N}}\right] / 5, \\
R V_{M, t+\frac{i}{N}} & \equiv R V_{\left(t+\frac{i}{N}\right)-20, t+\frac{i}{N}}=\left[R V_{\left(t+\frac{i}{N}\right)-20}+R V_{\left(t+\frac{i}{N}\right)-19}+\ldots+R V_{t+\frac{i}{N}}\right] / 21
\end{aligned}
$$

as the daily, weakly, and monthly realized variance on day $t+\frac{i}{N}$, respectively. ${ }^{22}$ Further, $R V_{\left(t+\frac{i}{N}\right)+1,\left(t+\frac{i}{N}\right)+20}$ is the realized variance over the next 21 days, i.e.:

$$
R V_{\left(t+\frac{i}{N}\right)+1,\left(t+\frac{i}{N}\right)+20}=\left[R V_{\left(t+\frac{i}{N}\right)+1}+R V_{\left(t+\frac{i}{N}\right)+2}+\ldots+R V_{\left(t+\frac{i}{N}\right)+20}\right] / 21
$$

Finally, to compute $R V_{t}^{H A R}$, we run the following regression:

$$
\begin{aligned}
R V_{\left(t+\frac{i}{N}\right)+1,\left(t+\frac{i}{N}\right)+20}=\phi_{0} & +\phi_{D} R V_{D, t+\frac{i}{N}}+\phi_{W} R V_{W, t+\frac{i}{N}} \\
& +\phi_{M} R V_{M, t+\frac{i}{N}}+\epsilon_{\left(t+\frac{i}{N}\right)+1,\left(t+\frac{i}{N}\right)+20}
\end{aligned}
$$

where $\phi_{0}, \phi_{D}, \phi_{W}$, and $\phi_{M}$ are the regression coefficients, and $\epsilon_{\left(t+\frac{i}{N}\right)+1,\left(t+\frac{i}{N}\right)+20}$ is the error term over the next 21 days. The fitted values are the forecasted $R V$ and represent $R V_{t}^{H A R}$.

Downside and Upside Variance Risk Premium We define the downside and upside variance risk premium $\left(V R P^{D O W N}\right.$ and $\left.V R P^{U P}\right)$ as the difference between the downside and upside model-free implied variance $\left(\left(\sigma_{t}^{\mathbb{Q}-}\right)^{2}\right.$ and $\left.\left(\sigma_{t}^{\mathbb{Q}+}\right)^{2}\right)$ and the downside and upside

\footnotetext{
${ }^{22}$ Since we now work with daily rather than intraday data, we follow the common approach and define one month as 21 trading days.
} 
realized variance $\left(R V^{D O W N}\right.$ and $\left.R V^{U P}\right)$, respectively:

$$
\begin{aligned}
V R P_{t}^{D O W N} & =\left(\sigma_{t}^{\mathbb{Q}-}\right)^{2}-R V_{t}^{D O W N}, \\
V R P_{t}^{U P} & =\left(\sigma_{t}^{\mathbb{Q}+}\right)^{2}-R V_{t}^{U P} .
\end{aligned}
$$

To obtain $\left(\sigma_{t}^{\mathbb{Q}-}\right)^{2}$ and $\left(\sigma_{t}^{\mathbb{Q}+}\right)^{2}$, we follow Andersen \& Bondarenko (2010) and Andersen et al. (2015) and use their corridor implied volatility method to decompose the model-free implied variance into different parts, and define the model-free implied variance $\left(\left(\sigma_{t}^{\mathbb{Q}}\right)^{2}\right)$ as:

$$
\left(\sigma_{t}^{\mathbb{Q}}\right)^{2}=2 \int_{0}^{\infty} \frac{M(K)}{K^{2}} d K=\left(\sigma_{t}^{\mathbb{Q}-}\right)^{2}+\left(\sigma_{t}^{\mathbb{Q}+}\right)^{2},
$$

where $M(K)=\min (P(K), C(K))$ is the minimum price of the put and call with maturity of 1 month and strike $K$. Consistently, we also compute the grid of 1,000 equidistant interpolated moneyness levels of out-of-the money option prices, as described above. Finally, to compute $\left(\sigma_{t}^{\mathbb{Q}-}\right)^{2}$ and $\left(\sigma_{t}^{\mathbb{Q}+}\right)^{2}$, we assume the threshold $S e^{\theta}$ with $\theta=0$ :

$$
\begin{aligned}
& \left(\sigma_{t}^{\mathbb{Q}-}\right)^{2}=2 \int_{0}^{S e^{\theta}} \frac{M(K)}{K^{2}} d K, \\
& \left(\sigma_{t}^{\mathbb{Q}+}\right)^{2}=2 \int_{S e^{\theta}}^{\infty} \frac{M(K)}{K^{2}} d K .
\end{aligned}
$$

We then use the trapezoidal rule to approximate the integrals, as outlined above.

Following Barndorff-Nielsen et al. (2010), we decompose the realized variance into the upside and downside realized variance for a given threshold $\kappa$. Imposing $\kappa=0$, we compute $R V_{t}^{D O W N}\left(R V_{t}^{U P}\right)$ on the basis of Equation (2), however, using only log-returns that are at most (least) equal to $\kappa$.

Downside and Upside Variance Risk Premium based on HAR-RV Model We define the downside and upside variance risk premium based on the $H A R-R V$ model 
$\left(V R P^{D O W N, H A R}\right.$ and $\left.V R P^{U P, H A R}\right)$ as the difference between the downside and upside model-free implied variance $\left(\left(\sigma_{t}^{\mathbb{Q}-}\right)^{2}\right.$ and $\left.\left(\sigma_{t}^{\mathbb{Q}+}\right)^{2}\right)$ and the downside and upside realized variance, estimated on the basis of the $H A R$ model $\left(R V^{D O W N, H A R}\right.$ and $\left.R V^{U P, H A R}\right)$, respectively:

$$
\begin{aligned}
V R P_{t}^{D O W N, H A R} & =\left(\sigma_{t}^{\mathbb{Q}-}\right)^{2}-R V_{t}^{D O W N, H A R}, \\
V R P_{t}^{U P, H A R} & =\left(\sigma_{t}^{\mathbb{Q}+}\right)^{2}-R V_{t}^{U P, H A R},
\end{aligned}
$$

where $\left(\sigma_{t}^{\mathbb{Q}-}\right)^{2}$ and $\left(\sigma_{t}^{\mathbb{Q}+}\right)^{2}$ are as previously defined. To compute $R V_{t}^{D O W N, H A R}\left(R V_{t}^{U P, H A R}\right)$, we follow the steps described above, however, using $R V^{D O W N}\left(R V^{U P}\right)$ instead of $R V$.

\section{V.B Results}

Table A3 of the Online Appendix reports the regression results for the different specifications predicting the next month's excess return and realized variance, respectively. In Panel A, we observe that all specifications exhibit an inferior performance in predicting excess returns compared to the $V R P$ as proposed by Bollerslev et al. (2009). However, we notice that $V R P^{U P}, V R P^{D O W N}$, and $V R P^{U P, H A R}$ have still (in-sample) significant predictive power, indicated by $t$-statistics between 2.47 and 2.17 , and in-sample $R^{2} s$ from $2.65 \%$ to $2.05 \%$.

In Panel B of Table A3 of the Online Appendix, we find that all specifications have a similar (insignificant) in-sample predictive power for $R V$ as $V R P$. We observe noteworthy significant out-of-sample predictability for $\operatorname{VRP} P^{H A R}\left(R_{\text {oos }}^{2}=3.40 \%\right), V R P^{D O W N}\left(R_{\text {oos }}^{2}=\right.$ $4.34 \%)$, and $V R P^{U P, H A R}\left(R_{\text {oos }}^{2}=4.63 \%\right)$.

We now turn our attention to the portfolio choice implications. Table A4 of the Online Appendix reports the results of the economic value. For an agent with risk-aversion of $\gamma=3$, we observe that $V R P^{U P}\left(V R P^{D O W N}\right)$ provides substantial improvements in the utility gain 
of $6.74 \%$ p.a. (6.31\% p.a.) and in the Sharpe Ratio of $0.71(0.59)$.

Overall, the results confirm our previous findings in providing evidence for a stronger variance than return predictability. We also observe that $V R P^{D O W N}, V R P^{U P}$, and $V R P^{U P, H A R}$ predict in-sample both returns and realized variance. In addition, we notice that $V R P^{H A R}, V R P^{D O W N}$, and $V R P^{U P, H A R}$ strongly predict realized variance out-of-sample.

Finally, the results reveal that $V R P^{U P}$ and $V R P^{D O W N}$ provide evidence for generating statistically significant economic value.

\section{V.C Alternative Approach of Variance Predictability}

In our main analysis, we included lagged realized variance as an additional predictor when predicting realized variance, as it is well known that variance is a persistent process. To see whether our results are driven by this choice, we repeat the analysis without including lagged realized variance. We now estimate the following regression model for realized variance:

$$
R V_{t+1}=\gamma_{0}+\gamma_{1} X_{t}+\epsilon_{t+1}
$$

where all variables are as previously defined. Under the null hypothesis of no predictability, the variable $X_{t}$ has no predictive power for future realized variance. In this case, we expect that $\gamma_{1}=0$, and that the best estimate for future realized variance would be its mean. Accordingly, the historical mean variance serves as benchmark model. Using this specification, we are able to analyze the individual predictive power of variables subject to the standard approach in extant literature. Tables A5 and A6 of the Online Appendix summarize the results of the predictability and economic value analysis.

In Table A5, we find that all variables, except $F H$, have in-sample predictive power for future realized variance. $C R P$ turns out to have significant predictive ability, indicated by a $t$-statistic of -3.72 . We notice that the in-sample $R^{2} s$ are smaller compared with our 
previous results. They range from $3.19 \%$ for $S K E W^{B K M}$ to $38.83 \%$ for $V A R^{B K M}$.

In the out-of-sample analysis, we observe that in general the variables that predict realized variance in-sample are also predictors out-of-sample. All variables, with the exception of $F H, G M R$, and $V R P$, yield an improvement relative to the recursive mean. The reason for the poor behavior of these three variables is likely twofold: $F H$ and $G M R$ perform poorly in general and the $V R P$ exhibits a sign-switching behavior as discussed previously. The $R_{\text {oos }}^{2} s$ range from $1.88 \%$ for $C R P$ to $34.65 \%$ for $V A R^{B K M}$. It seems that, using the standard methodology, the predictive power of some variables increases, compared to our previous results.

In the economic value analysis, shown in Table A6, we find similar results as before. It seems that statistical evidence of predictability does not necessarily imply important economic gains. One can see that relative to an agent with risk-aversion $\gamma=3$ who assumes that the market excess return and the realized variance are unpredictable, the agent who exploits the information content of $C R P$ would improve her utility by $4.63 \%$ p.a. Overall, the results confirm our previous findings.

\section{Conclusion}

This paper comprehensively studies the predictive power of option-implied variables for future excess returns and realized variance. A variable is considered to have predictive power if it exhibits statistically significant forecasting power and also adds economic value. We find that the correlation risk premium and the variance risk premium emerge as statistically significant predictors of both the market excess return and the realized variance. This is true both in- and out-of-sample.

We then investigate the economic value of the documented predictability. Our results highlight an important contrast between the two variables. Relative to a naive strategy that 
assumes that excess returns and realized variance are unpredictable, the agent who relies on the correlation risk premium as a timing signal realizes utility gains of $5.03 \%$ p.a. In contrast, the timing strategy that uses the variance risk premium as timing signal yields lower certainty equivalent returns than a naive strategy that assumes constant excess returns and realized variance. Thus, our analysis shows that statistical evidence of predictability does not necessarily translate into economic value. Moreover, we find that forecast combinations generate stable forecasts for both excess returns and realized variance, and that they add substantial economic value.

We further decompose the total variance risk premium into the downside and upside components, and analyze the predictability of different versions of the variance risk premium. We show that the upside and downside variance risk premia have noteworthy (in-sample) predictive power for excess returns and realized variance. Further, a timing strategy provides substantial utility gains.

Future research could analyze the predictive power of option-implied variables for specific industry returns as well as different asset classes. Furthermore, we believe that it would be interesting to study whether the $C R P$ performs similarly well in predicting equity returns in further developed and emerging markets. Finally, it could be interesting to test whether forward-looking option-implied information drives out the predictive power of U.S. returns for developed and emerging countries, as documented by Rapach et al. (2013). 


\section{Bibliography}

Andersen, T. G., Bollerslev, T., Diebold, F. X., \& Labys, P. (2003). Modeling and forecasting realized volatility. Econometrica, $71(2), 579-625$.

Andersen, T. G., \& Bondarenko, O. (2010). Dissecting the pricing of equity index volatility. Working Paper.

Andersen, T. G., Bondarenko, O., \& Gonzalez-Perez, M. T. (2015). Exploring return dynamics via corridor implied volatility. Review of Financial Studies, 28(10), 2902-2945.

Aumann, R. J., \& Serrano, R. (2008). An economic index of riskiness. Journal of Political Economy, 116(5), 810-836.

Bakshi, G., Kapadia, N., \& Madan, D. (2003). Stock return characteristics, skew laws, and the differential pricing of individual equity options. Review of Financial Studies, 16(1), $101-143$.

Balduzzi, P., \& Lynch, A. W. (1999). Transaction costs and predictability: Some utility cost calculations. Journal of Financial Economics, 52(1), 47-78.

Bali, T. G., Cakici, N., \& Chabi-Yo, F. (2011). A generalized measure of riskiness. Management Science, 57(8), 1406-1423.

Bali, T. G., Cakici, N., \& Chabi-Yo, F. (2012). Does aggregate riskiness predict future economic downturns? Working Paper.

Bali, T. G., Cakici, N., \& Chabi-Yo, F. (2015). A new approach to measuring riskiness in the equity market: Implications for the risk premium. Journal of Banking 86 Finance, 57, $101-117$.

Bali, T. G., \& Hovakimian, A. (2009). Volatility spreads and expected stock returns. Management Science, 55(11), 1797-1812.

Bali, T. G., Hu, J., \& Murray, S. (2017). Option implied volatility, skewness, and kurtosis and the cross-section of expected stock returns. Working Paper.

Barndorff-Nielsen, O. E., Kinnebrock, S., \& Shephard, N. (2010). Volatility and time series econometrics: Essays in honor of Robert Engle. Oxford University Press.

Black, F., \& Scholes, M. (1973). The pricing of options and corporate liabilities. Journal of Political Economy, 81(3), 637-654.

Bollerslev, T., Marrone, J., Xu, L., \& Zhou, H. (2014). Stock return predictability and variance risk premia: Statistical inference and international evidence. Journal of Financial and Quantitative Analysis, 49(3), 633-661.

Bollerslev, T., Tauchen, G., \& Zhou, H. (2009). Expected stock returns and variance risk premia. Review of Financial Studies, 22(11), 4463-4492. 
Buss, A., Schönleber, L., \& Vilkov, G. (2018). Expected stock returns and the correlation risk premium. Working Paper.

Çakmaklı, C., \& van Dijk, D. (2016). Getting the most out of macroeconomic information for predicting excess stock returns. International Journal of Forecasting, 32(3), 650-668.

Campbell, J. Y., \& Thompson, S. B. (2008). Predicting excess stock returns out of sample: Can anything beat the historical average? Review of Financial Studies, 21 (4), 1509-1531.

Chang, B.-Y., Christoffersen, P., Jacobs, K., \& Vainberg, G. (2012). Option-implied measures of equity risk. Review of Finance, 16, 385-428.

Christoffersen, P. F. (2012). Elements of financial risk management. 2nd Edition. Academic Press.

Corsi, F. (2009). A simple approximate long-memory model of realized volatility. Journal of Financial Econometrics, 7(2), 174-196.

Cosemans, M. (2011). The pricing of long and short run variance and correlation risk in stock returns. Working Paper.

Cremers, M., \& Weinbaum, D. (2010). Deviations from put-call parity and stock return predictability. Journal of Financial and Quantitative Finance, 45(2), 335-367.

DeMiguel, V., Garlappi, L., \& Uppal, R. (2009). Optimal versus naive diversification: How inefficient is the 1/n portfolio strategy? Review of Financial Studies, 22(5), 1915-1953.

Drechsler, I., \& Yaron, A. (2011). What's vol got to do with it. Review of Financial Studies, $24(1), 1-45$.

Driessen, J., Maenhout, P. J., \& Vilkov, G. (2009). The price of correlation risk: Evidence from equity options. Journal of Finance, 64(3), 1377-1406.

Driessen, J., Maenhout, P. J., \& Vilkov, G. (2013). Option-implied correlations and the price of correlation risk. Working Paper.

Du, J., \& Kapadia, N. (2012). The tail in the volatility index. Working Paper.

Feunou, B., Jahan-Parvar, M. R., \& Okou, C. (2015). Downside variance risk premium. Working Paper.

Figlewski, S. (2010). Estimating the implied risk neutral density. In T. Bollerslev, J. Russell, \& M. Watson (Eds.) Volatility and Time Series Econometrics: Essays in Honor of Robert Engle. Oxford University Press.

Fleming, J., Kirby, C., \& Ostdiek, B. (2001). The economic value of volatility timing. Journal of Finance, 56(1), 329-352.

Foster, D. P., \& Hart, S. (2009). An operational measure of riskiness. Journal of Political Economy, 117(5), 785-814. 
Goyal, A., \& Welch, I. (2003). Predicting the equity premium with dividend ratios. Management Science, 49(5), 639-654.

Goyal, A., \& Welch, I. (2008). A comprehensive look at the empirical performance of equity premium prediction. Review of Financial Studies, 21 (4), 1455-1508.

Jiang, G. J., \& Tian, Y. S. (2005). The model-free implied volatility and its information content. Review of Financial Studies, 18(4), 1305-1342.

Jobson, J. D., \& Korkie, B. M. (1981). Performance hypothesis testing with the Sharpe and Treynor measures. Journal of Finance, 36(4), 889-908.

Jordan, S. J., Vivian, A., \& Wohar, M. E. (2017). Forecasting market returns: Bagging or combining? International Journal of Forecasting, 33(1), 102-120.

Jordan, S. J., Vivian, A. J., \& Wohar, M. E. (2014). Forecasting returns: New European evidence. Journal of Empirical Finance, 26, 76-95.

Kourtis, A., Markellos, R. N., \& Symeonidis, L. (2016). An international comparison of implied, realized, and GARCH volatility forecasts. Journal of Futures Markets, 36(12), 1164-1193.

Leiss, M., \& Nax, H. H. (2018). Option-implied objective measures of market risk. Journal of Banking \& Finance, 88, 241-249.

Leiss, M., Nax, H. H., \& Sornette, D. (2015). Super-exponential growth expectations and the global financial crisis. Journal of Economic Dynamics and Control, 55, 1-13.

Maio, P., \& Santa-Clara, P. (2012). Multifactor models and their consistency with the ICAPM. Journal of Financial Economics, $106(3)$, 586-613.

McCracken, M. W. (2007). Asymptotics for out of sample tests of Granger causality. Journal of Econometrics, 140(2), 719-752.

McGee, R. J., \& McGroarty, F. (2017). The risk premium that never was: A fair value explanation of the volatility spread. European Journal of Operational Research, 262(1), $370-380$.

Memmel, C. (2003). Performance hypothesis testing with the Sharpe ratio. Finance Letters, $1(1)$.

Merton, R. C. (1973). An intertemporal capital asset pricing model. Econometrica, 41(5), $867-887$.

Pollet, J. M., \& Wilson, M. (2010). Average correlation and stock market returns. Journal of Financial Economics, 96(3), 364-380.

Prokopczuk, M., \& Wese Simen, C. (2014). The importance of the volatility risk premium for volatility forecasting. Journal of Banking \& Finance, 40, 303-320. 
Pyun, S. (2016). Variance risk in aggregate stock returns and time-varying return predictability. Forthcoming in Journal of Financial Economics.

Rapach, D. E., Strauss, J. K., \& Zhou, G. (2010). Out-of-sample equity premium prediction: Combination forecasts and links to the real economy. Review of Financial Studies, 23(2), $821-862$.

Rapach, D. E., Strauss, J. K., \& Zhou, G. (2013). International stock return predictability: What is the role of the united states? Journal of Finance, 68(4), 1633-1662.

Rapach, D. E., \& Wohar, M. E. (2006). In-sample vs. out-of-sample tests of stock return predictability in the context of data mining. Journal of Empirical Finance, 13(2), 231-247.

Rapach, D. E., \& Zhou, G. (2013). Forecasting stock returns. Handbook of Economic Forecasting, 2(Part A), 328-383.

Rehman, Z., \& Vilkov, G. (2012). Risk-neutral skewness: Return predictability and its sources. Working Paper.

Richardson, M., \& Stock, J. H. (1989). Drawing inferences from statistics based on multiyear asset returns. Journal of Financial Economics, 25(2), 323-348.

Sévi, B. (2014). Forecasting the volatility of crude oil futures using intraday data. European Journal of Operational Research, 235(3), 643-659.

Stambaugh, R. F. (1999). Predictive regressions. Journal of Financial Economics, 54(3), $375-421$.

Stilger, P. S., Kostakis, A., \& Poon, S.-H. (2016). What does risk-neutral skewness tell us about future stock returns? Management Science, 63(6), 1814-1834.

Xing, Y., Zhang, X., \& Zhao, R. (2010). What does the individual option volatility smirk tell us about future equity returns? Journal of Financial and Quantitative Analysis, 45(3), 641-662.

Zhou, H. (2013). On the predictive power of the implied correlation index. Working Paper. 


\section{Figure 1: Return Predictability}

This figure plots the in- and out-of-sample performances of individual variables. We regress monthly excess returns on a constant and the lagged predictive variable. On the ordinate, there are the cumulative differences in squared forecast errors (CDSFE). The in-sample performance is the difference between the cumulative squared demeaned excess return and the cumulative squared regression residual, and the out-of-sample performance is the difference between the cumulative squared forecast error from the restricted model and the cumulative squared forecast error from the unrestricted model. The grey bars indicate the U.S. recessions, published by the NBER. All data are sampled at the monthly frequency and relate to the S\&P 500 index.

(a) $C R P$

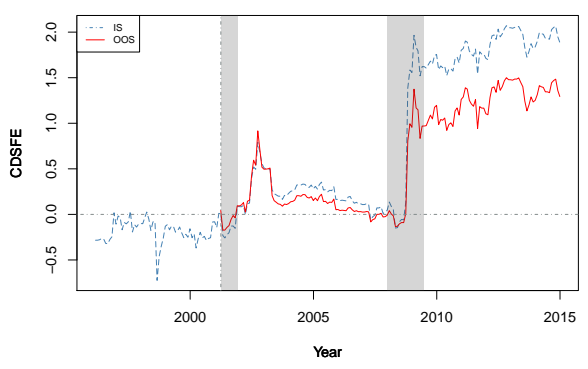

(b) $E X K U R T^{B K M}$

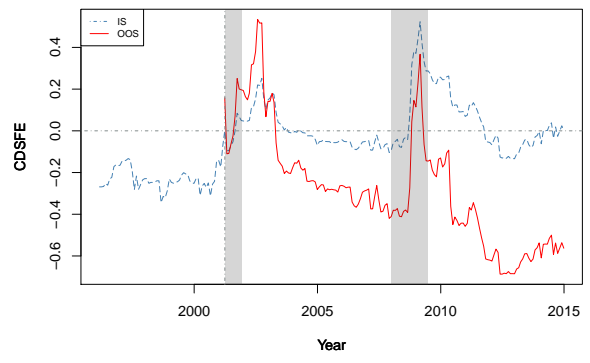

(c) $F H$

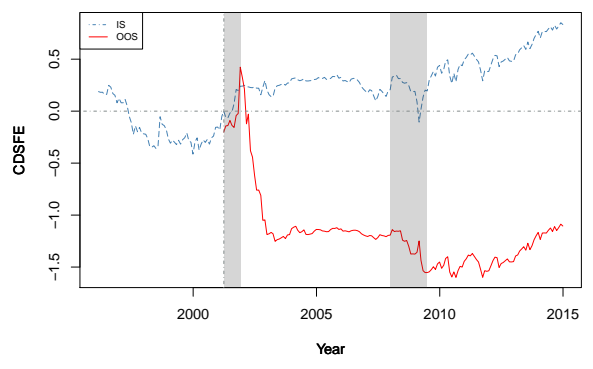

(d) $G M R$

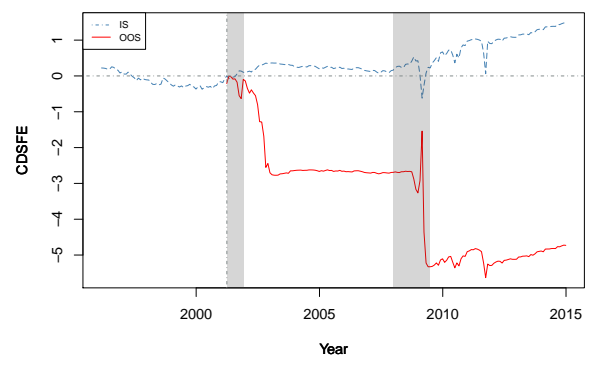

(e) $S K E W^{B K M}$

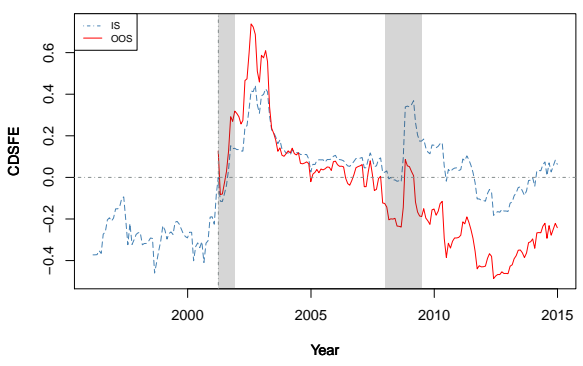

(f) $S M I R K$

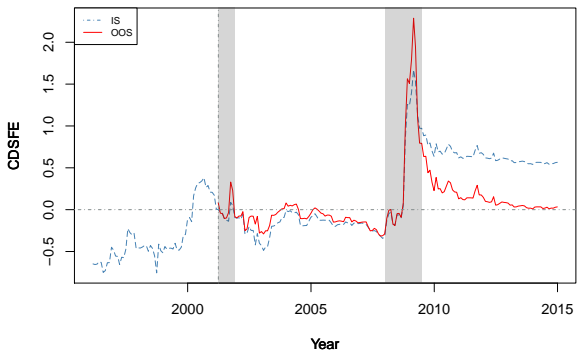

(g) $V A R^{B K M}$

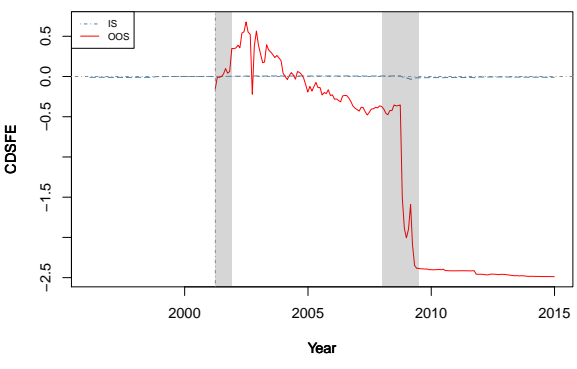

(h) $V R P$

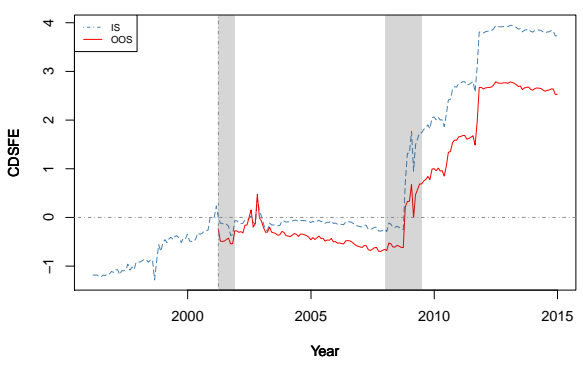




\section{Figure 2: Variance Predictability}

This figure plots the in- and out-of-sample performances of individual variables. We regress monthly realized variance on a constant, the lagged predictive variable, and the lagged realized variance. On the ordinate, there are the cumulative differences in squared forecast errors (CDSFE). The in-sample performance is the difference between the cumulative squared demeaned excess return and the cumulative squared regression residual, and the out-of-sample performance is the difference between the cumulative squared forecast error from the restricted model and the cumulative squared forecast error from the unrestricted model. The grey bars indicate the U.S. recessions, published by the NBER. All data are sampled at the monthly frequency and relate to the S\&P 500 index.

(a) $C R P$

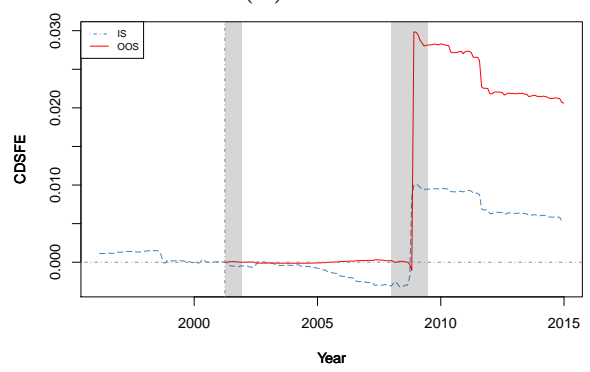

(b) $E X K U R T^{B K M}$

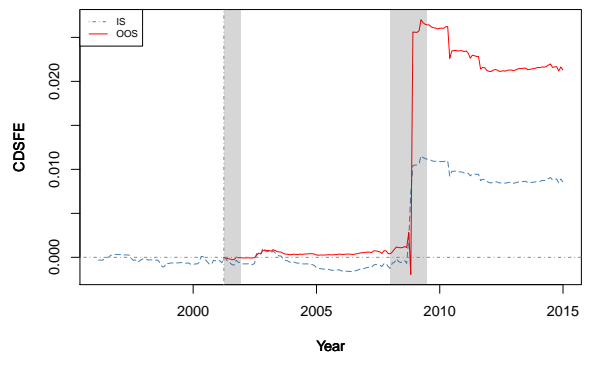

(c) FH

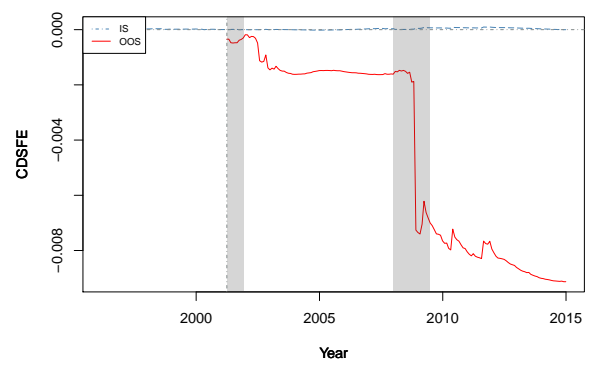

(d) $G M R$

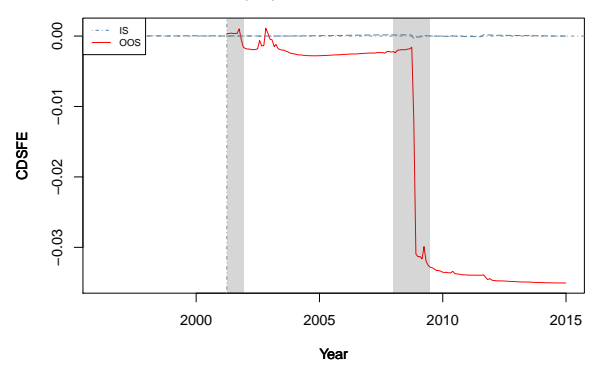

(e) $S K E W^{B K M}$

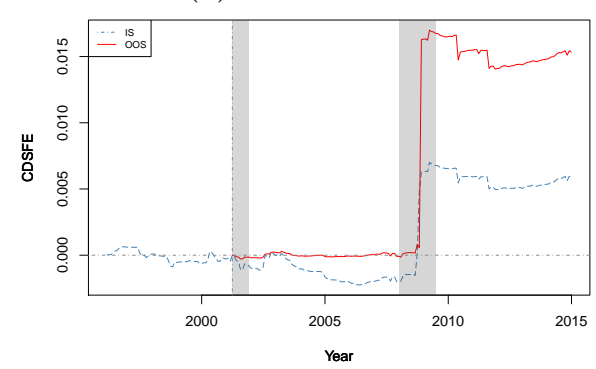

(f) $S M I R K$

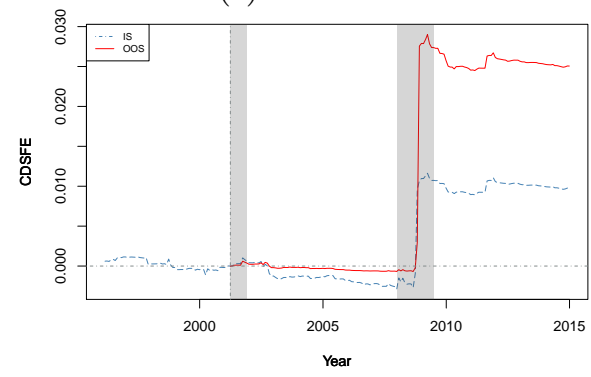

(g) $V A R^{B K M}$

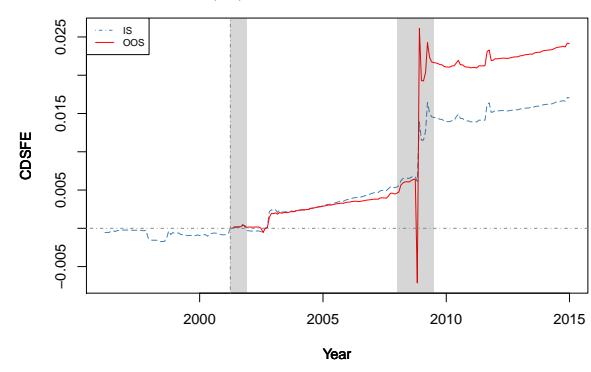

(h) $V R P$

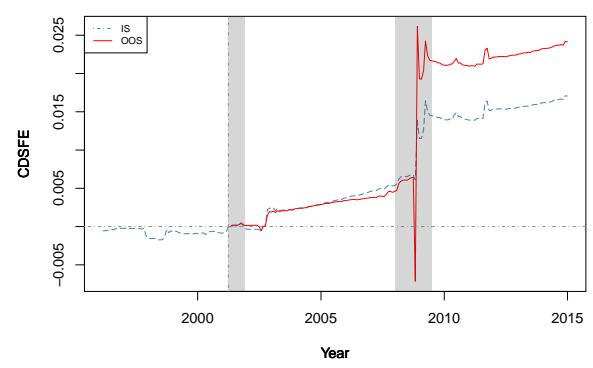




\section{Table I: Summary Statistics}

This table summarizes key statistics about several variables. CRP denotes the correlation risk premium. $I C$ is the implied correlation. $R C$ is the realized correlation. ER is the market excess return. EXKURT ${ }^{B K M}$ is the risk-neutral kurtosis of Bakshi et al. (2003). FH is the risk-neutral riskiness measure of Leiss $\&$ Nax (2018). GMR is the generalized measure of riskiness of Bali et al. (2011). $R V$ is the realized variance. SKEW ${ }^{B K M}$ is the risk-neutral skewness of Bakshi et al. (2003). SMIRK is the option smirk. $V A R^{B K M}$ is the risk-neutral variance of Bakshi et al. (2003). VRP is the variance risk premium computed as the difference between the risk-neutral variance of Bakshi et al. (2003) and the most recent observation of the realized variance. $V R P^{H A R}$ denotes the variance risk premium based on the HAR-RV model. $V R P^{D O W N}$ is the downside variance risk premium. $V R P^{U P}$ is the upside variance risk premium. $V R P^{D O W N, H A R}$ is the downside variance risk premium based on the $H A R-R V$ model. Finally, $V R P^{U P, H A R}$ is the upside variance risk premium based on the HAR-RV model. "Mean", "Std Dev", "Skew", and "Kurt" denote the mean, standard deviation, skewness, and kurtosis, respectively. The last two columns show the $A R(1)$ coefficient and the number of observations, respectively. All data are sampled at the monthly frequency and relate to the S\&P 500 index.

\begin{tabular}{lcccccc}
\hline \hline & Mean & Std Dev & Skew & Kurt & AR $(1)$ & Nobs \\
\hline$C R P$ & 0.0941 & 0.1019 & 0.1409 & 3.2970 & 0.2496 & 228 \\
$I C$ & 0.4166 & 0.1403 & 0.5092 & 3.1725 & 0.7621 & 228 \\
$R C$ & 0.3225 & 0.1398 & 0.8731 & 3.5571 & 0.5854 & 228 \\
$E R$ & 0.0591 & 0.1555 & -0.8294 & 4.4268 & 0.0900 & 228 \\
$E X K U R T^{B K M}$ & 0.7571 & 0.2840 & 0.4887 & 3.0378 & 0.7522 & 228 \\
$F H$ & 0.4302 & 0.3250 & 0.0241 & 1.4467 & 0.9250 & 228 \\
$G M R$ & 9.0972 & 12.5814 & 2.3413 & 11.0123 & 0.8818 & 228 \\
$R V$ & 0.0317 & 0.0519 & 7.3129 & 75.2277 & 0.6333 & 228 \\
$S K E W^{B K M}$ & -0.8698 & 0.1978 & 0.2588 & 3.0325 & 0.6611 & 228 \\
$S M I R K$ & 0.1326 & 0.2522 & 0.1584 & 3.4828 & 0.3299 & 228 \\
$V A R^{\text {BKM }}$ & 0.0474 & 0.0427 & 3.3066 & 18.0518 & 0.7880 & 228 \\
$V R P$ & 0.0157 & 0.0284 & -5.0586 & 61.7528 & 0.1340 & 228 \\
$V R P^{H A R}$ & 0.0459 & 0.0414 & 3.2330 & 17.3103 & 0.7887 & 228 \\
$V R P^{\text {DOWN }}$ & -0.0136 & 0.0249 & -7.5246 & 79.4665 & 0.5899 & 228 \\
$V R P^{U P}$ & -0.0143 & 0.0244 & -7.5439 & 78.4141 & 0.6219 & 228 \\
$V R P^{D O W N, H A R}$ & 0.0016 & 0.0015 & 2.7589 & 13.2030 & 0.7708 & 228 \\
$V R P^{U P, H A R}$ & 0.0007 & 0.0007 & 1.7649 & 7.6611 & 0.5894 & 228 \\
\hline \hline
\end{tabular}



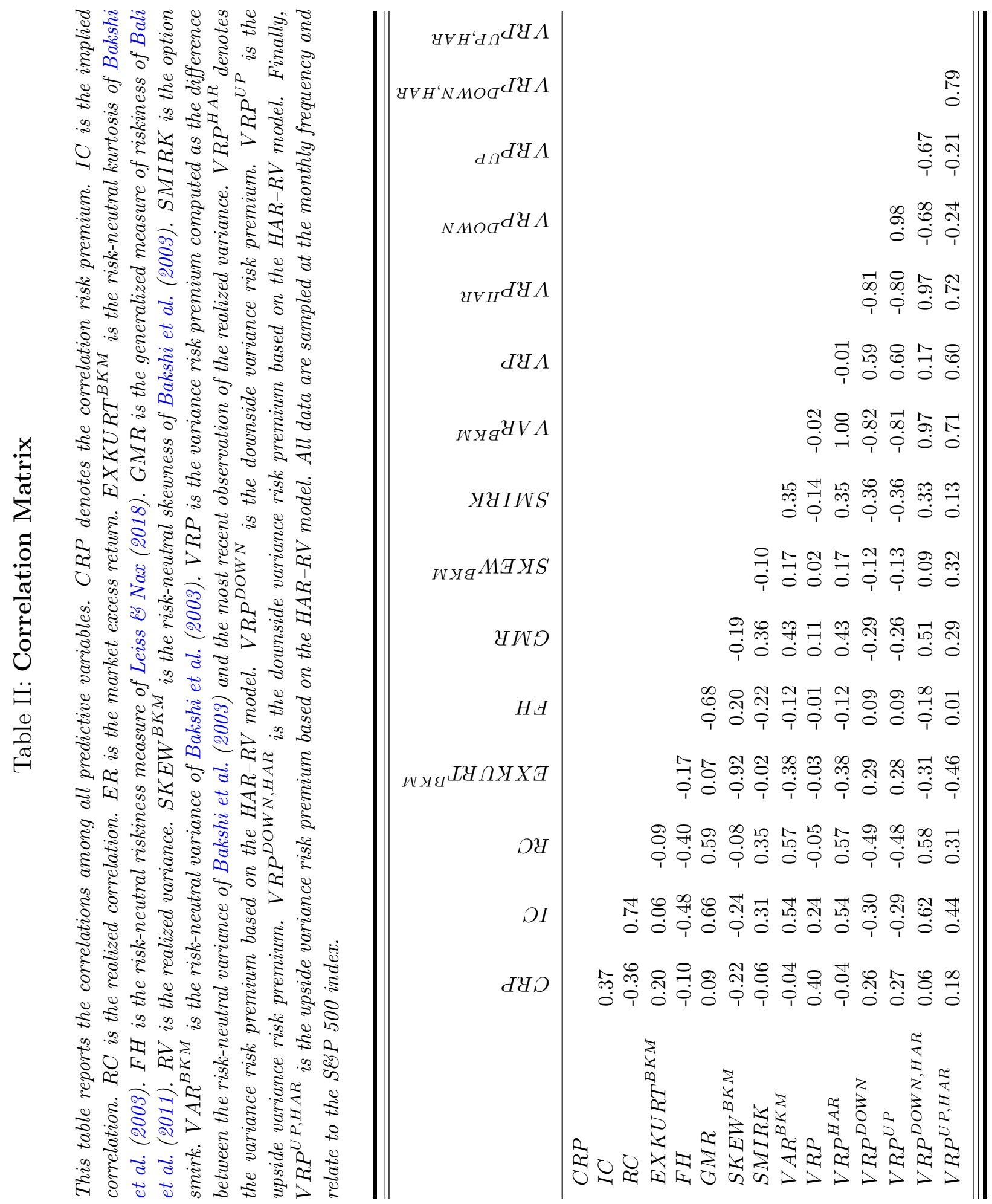


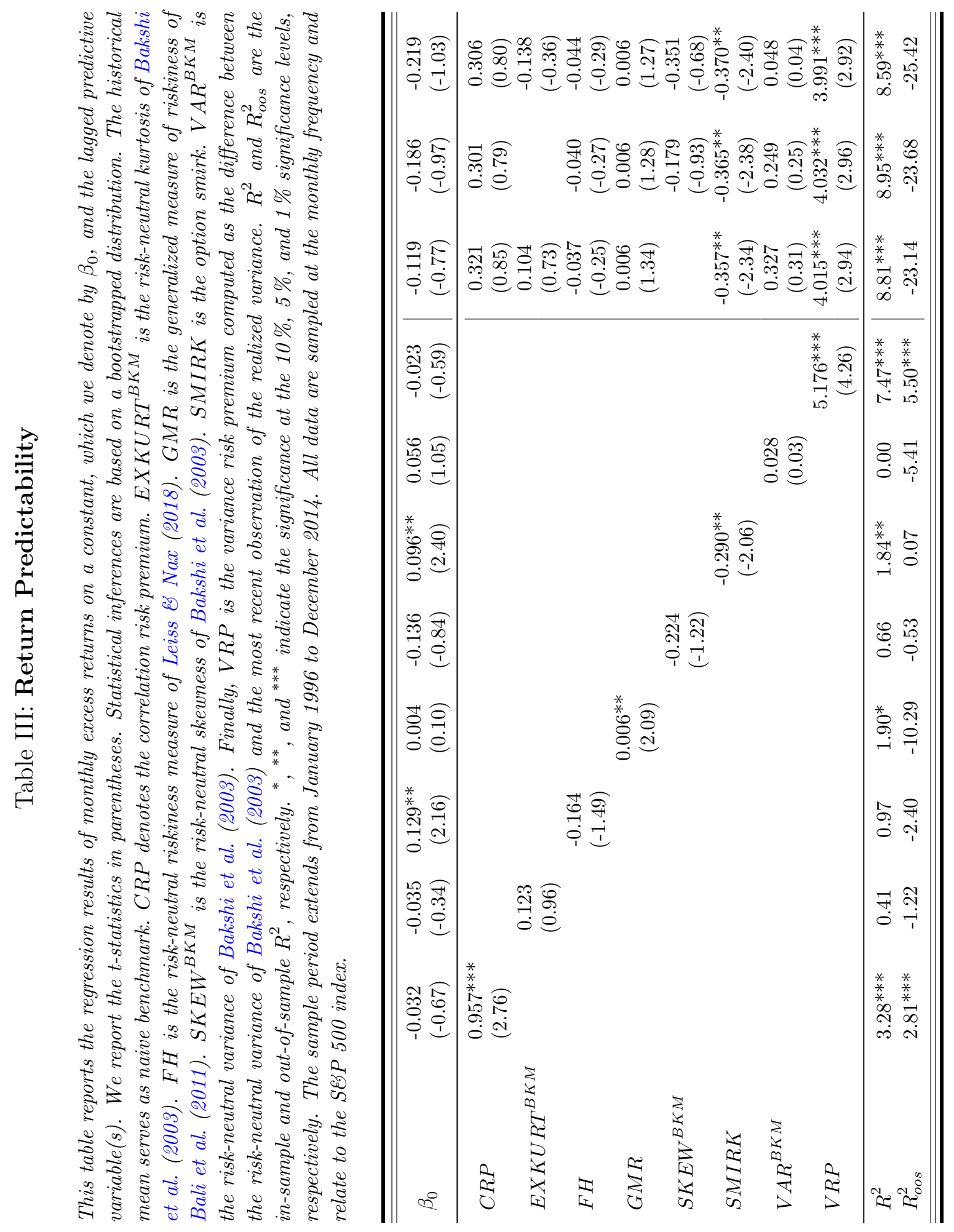




\section{Table IV: Variance Predictability}

This table reports the regression results of monthly realized variance on a constant, which we denote by $\gamma_{0}$, the lagged predictive variable, and the lagged realized variance $R V$. We report the t-statistics in parentheses. Statistical inferences are based on a bootstrapped distribution. The forecast of a fitted AR(1) model serves as naive benchmark. CRP denotes the correlation risk premium. EXKURT $T^{B K M}$ is the risk-neutral kurtosis of Bakshi et al. (2003). FH is the risk-neutral riskiness measure of Leiss 83 Nax (2018). GMR is the generalized measure of riskiness of Bali et al. (2011). $S K E W^{B K M}$ is the risk-neutral skewness of Bakshi et al. (2003). SMIRK is the option smirk. $V A R^{B K M}$ is the risk-neutral variance of Bakshi et al. (2003). Finally, VRP is the variance risk premium computed as the difference between the risk-neutral variance of Bakshi et al. (2003) and the most recent observation of the realized variance. $R^{2}$ and $R_{\text {oos }}^{2}$ are the in-sample and out-of-sample $R^{2}$, respectively. ${ }^{*},{ }^{* *}$, and ${ }^{* * *}$ indicate the significance at the $10 \%, 5 \%$, and $1 \%$ significance levels, respectively. The sample period extends from January 1996 to December 2014. All data are sampled at the monthly frequency and relate to the SEP 500 index.

\begin{tabular}{|c|c|c|c|c|c|c|c|c|}
\hline$\gamma_{0}$ & $\begin{array}{l}0.016^{* * *} \\
(3.80)\end{array}$ & $\begin{array}{c}0.031^{* * *} * \\
(3.57)\end{array}$ & $\begin{array}{c}0.012^{* *} \\
(2.43)\end{array}$ & $\begin{array}{c}0.011^{* * *} \\
(3.28)\end{array}$ & $\begin{array}{c}0.035^{* * *} \\
(2.78)\end{array}$ & $\begin{array}{c}0.010^{* * *} \\
(2.98)\end{array}$ & $\begin{array}{l}0.002 \\
(0.49)\end{array}$ & $\begin{array}{l}0.002 \\
(0.49)\end{array}$ \\
\hline$R V$ & $\begin{array}{l}0.612^{* * *} \\
(11.51)\end{array}$ & $\begin{array}{c}0.596^{* * *} \\
(11.14)\end{array}$ & $\begin{array}{c}0.633^{* * *} \\
(12.20)\end{array}$ & $\begin{array}{c}0.631^{* * *} \\
(11.66)\end{array}$ & $\begin{array}{c}0.621^{* * *} \\
(12.01)\end{array}$ & $\begin{array}{c}0.585^{* * *} \\
(10.67)\end{array}$ & $\begin{array}{c}0.374^{* * *} \\
(4.06)\end{array}$ & $\begin{array}{c}0.750^{* * *} \\
(12.26)\end{array}$ \\
\hline$C R P$ & $\begin{array}{l}-0.043 \\
(-1.59)\end{array}$ & & & & & & & \\
\hline$E X K U R T^{B K M}$ & & $\begin{array}{c}-0.024^{* *} \\
(-2.37)\end{array}$ & & & & & & \\
\hline$F H$ & & & $\begin{array}{c}0.000 \\
(-0.05)\end{array}$ & & & & & \\
\hline$G M R$ & & & & $\begin{array}{l}0.000 \\
(0.15)\end{array}$ & & & & \\
\hline$S K E W^{B K M}$ & & & & & $\begin{array}{c}0.026^{*} \\
(1.91)\end{array}$ & & & \\
\hline$S M I R K$ & & & & & & $\begin{array}{c}0.027^{* *} \\
(2.40)\end{array}$ & & \\
\hline$V A R^{B K M}$ & & & & & & & $\begin{array}{c}0.376^{* * *} \\
(3.37)\end{array}$ & \\
\hline$V R P$ & & & & & & & & $\begin{array}{c}0.376^{* * *} \\
(3.37)\end{array}$ \\
\hline$R^{2}$ & $40.80^{* *}$ & $41.60^{* *}$ & 40.13 & 40.14 & $41.09^{* *}$ & $41.64^{* *}$ & $43.03^{* *}$ & $43.03^{* *}$ \\
\hline$R_{\text {oos }}^{2}$ & $3.18^{* * *}$ & $3.34^{* * *}$ & -1.41 & -5.42 & $2.40^{* * *}$ & $3.89^{* * *}$ & $3.78^{* * *}$ & $3.78^{* * *}$ \\
\hline
\end{tabular}




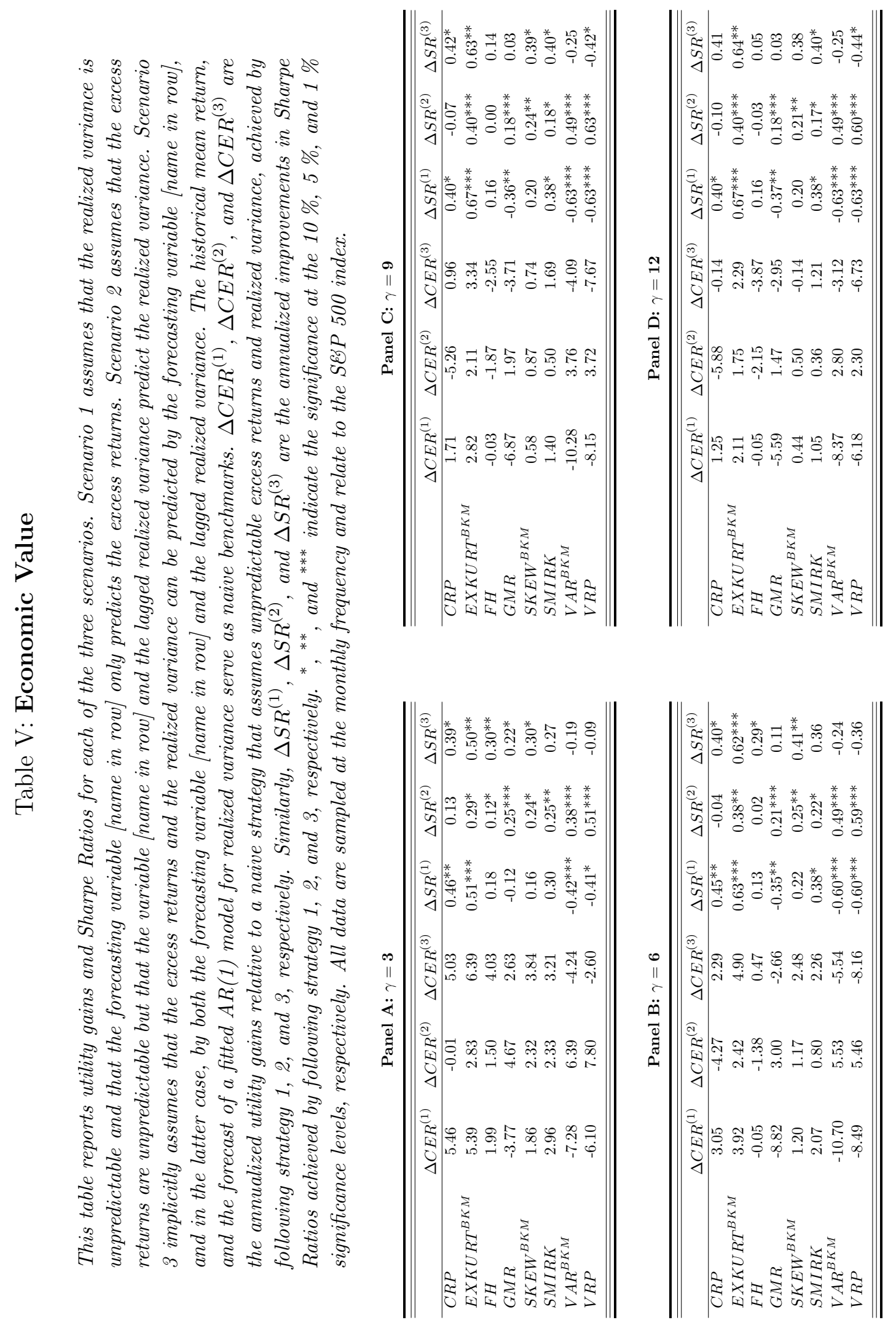




\section{Table VI: Out-of-Sample Analysis: Restriction}

This table reports the results of the out-of-sample analysis after imposing economically motivated restrictions. We report the MSE-F statistics in parenthesis. CRP denotes the correlation risk premium. EXKURT $T^{B K M}$ is the risk-neutral kurtosis of Bakshi et al. (2003). FH is the riskneutral riskiness measure of Leiss $\&$ Nax (2018). GMR is the generalized measure of riskiness of Bali et al. (2011). SKEW ${ }^{B K M}$ is the risk-neutral skewness of Bakshi et al. (2003). SMIRK is the option smirk. $V A R^{B K M}$ is the risk-neutral variance of Bakshi et al. (2003). Finally, VRP is the variance risk premium computed as the difference between the risk-neutral variance of Bakshi et al. (2003) and the most recent observation of the realized variance. The historical mean return, and the forecast of a fitted AR(1) model for realized variance serve as naive benchmarks. "(I)" denotes the imposition of the first restriction, where we set the slope estimate in the out-of-sample analysis equal to zero, whenever its sign differs from that of the in-sample analysis. "(II)" denotes the imposition of the second restriction, where we set the forecast equal to zero, whenever it is negative. " $(I+I I) "$ denotes the joint imposition of both restrictions. $R_{\text {oos }}^{2}$ is the out-of-sample $R^{2} .^{*},{ }^{* *}$, and ${ }^{* * *}$ indicate statistical significance at the $10 \%, 5 \%$, and $1 \%$ significance levels, respectively. All data are sampled at the monthly frequency and relate to the SGP 500 index.

\section{Panel A: Return Predictability}

\begin{tabular}{|c|c|c|c|c|c|c|c|c|c|}
\hline & & $\frac{\vec{v}}{v}$ & 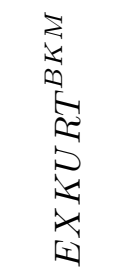 & $\sum_{1}$ & $\underset{\mho}{\longleftarrow}$ & 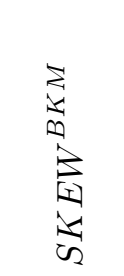 & $\frac{\sqrt{2}}{\sqrt{2}}$ & 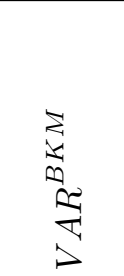 & $\frac{b}{s}$ \\
\hline (I) & $R_{\text {oos }}^{2}$ & $\begin{array}{c}2.81^{* * *} \\
(4.83)\end{array}$ & $\begin{array}{c}-1.22 \\
(-2.02)\end{array}$ & $\begin{array}{c}-2.70 \\
(-4.39)\end{array}$ & $\begin{array}{c}-3.27 \\
(-5.30)\end{array}$ & $\begin{array}{c}-0.53 \\
(-0.87)\end{array}$ & $\begin{array}{c}0.07 \\
(0.12)\end{array}$ & $\begin{array}{c}-3.84 \\
(-6.18)\end{array}$ & $\begin{array}{c}5.50^{* * *} \\
(9.73)\end{array}$ \\
\hline (II) & $R_{\text {oos }}^{2}$ & $\begin{array}{c}2.69^{* *} \\
(4.61)\end{array}$ & $\begin{array}{c}0.37 \\
(0.62)\end{array}$ & $\begin{array}{c}-1.40 \\
(-2.31)\end{array}$ & $\begin{array}{c}-3.69 \\
(-5.94)\end{array}$ & $\begin{array}{c}0.56 \\
(0.95)\end{array}$ & $\begin{array}{c}0.93 \\
(1.57)\end{array}$ & $\begin{array}{c}-3.39 \\
(-5.48)\end{array}$ & $\begin{array}{c}4.43^{* * *} \\
(7.74)\end{array}$ \\
\hline$(\mathrm{I}+\mathrm{II})$ & $R_{\text {oos }}^{2}$ & $\begin{array}{c}2.69 * * \\
(4.61)\end{array}$ & $\begin{array}{c}0.37 \\
(0.62)\end{array}$ & $\begin{array}{c}-1.38 \\
(-2.27)\end{array}$ & $\begin{array}{c}-3.27 \\
(-5.30)\end{array}$ & $\begin{array}{c}0.56 \\
(0.95)\end{array}$ & $\begin{array}{c}0.93 \\
(1.57)\end{array}$ & $\begin{array}{c}-2.95 \\
(-4.79)\end{array}$ & $\begin{array}{c}4.43^{* * *} \\
(7.74)\end{array}$ \\
\hline
\end{tabular}

Panel B: Variance Predictability

\begin{tabular}{|c|c|c|c|c|c|c|c|c|c|}
\hline & & $\frac{2}{0}$ & 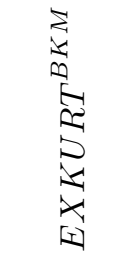 & $\underset{I_{1}}{\nabla_{1}}$ & $\sum_{\mho}^{\infty}$ & 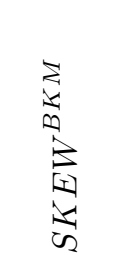 & $\frac{1}{\equiv}$ & 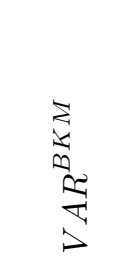 & $\frac{2}{2}$ \\
\hline (I) & $R_{o o s}^{2}$ & $\begin{array}{c}3.28^{* * *} \\
(5.67)\end{array}$ & $\begin{array}{c}3.34^{* * *} \\
(5.77)\end{array}$ & $\begin{array}{c}-1.82 \\
(-2.98)\end{array}$ & $\begin{array}{c}-11.23 \\
(-16.87)\end{array}$ & $\begin{array}{c}2.40^{* *} \\
(4.10)\end{array}$ & $\begin{array}{c}3.89 * * * \\
(6.76)\end{array}$ & $\begin{array}{c}3.78^{* * *} \\
(6.57)\end{array}$ & $\begin{array}{c}3.78^{* * *} \\
(6.57)\end{array}$ \\
\hline (II) & $R_{o o s}^{2}$ & $\begin{array}{c}3.18^{* *} \\
(5.48)\end{array}$ & $\begin{array}{c}3.44^{* * *} \\
(5.95)\end{array}$ & $\begin{array}{c}-1.41 \\
(-2.32)\end{array}$ & $\begin{array}{c}-5.42 \\
(-8.58)\end{array}$ & $\begin{array}{c}2.40^{* *} \\
(4.10)\end{array}$ & $\begin{array}{c}3.89^{* * *} \\
(6.76)\end{array}$ & $\begin{array}{c}3.78^{* * *} \\
(6.57)\end{array}$ & $\begin{array}{c}3.78^{* *} \\
(6.57)\end{array}$ \\
\hline$(\mathrm{I}+\mathrm{II})$ & $R_{o o s}^{2}$ & $\begin{array}{c}3.28^{* *} \\
(5.67)\end{array}$ & $\begin{array}{c}3.44^{* *} \\
(5.95)\end{array}$ & $\begin{array}{c}-1.82 \\
(-2.98)\end{array}$ & $\begin{array}{c}-11.23 \\
(-16.87)\end{array}$ & $\begin{array}{c}2.40^{* *} \\
(4.10)\end{array}$ & $\begin{array}{c}3.89 * * * \\
(6.76)\end{array}$ & $\begin{array}{c}3.78^{* *} \\
(6.57)\end{array}$ & $\begin{array}{c}3.78^{* *} \\
(6.57)\end{array}$ \\
\hline
\end{tabular}




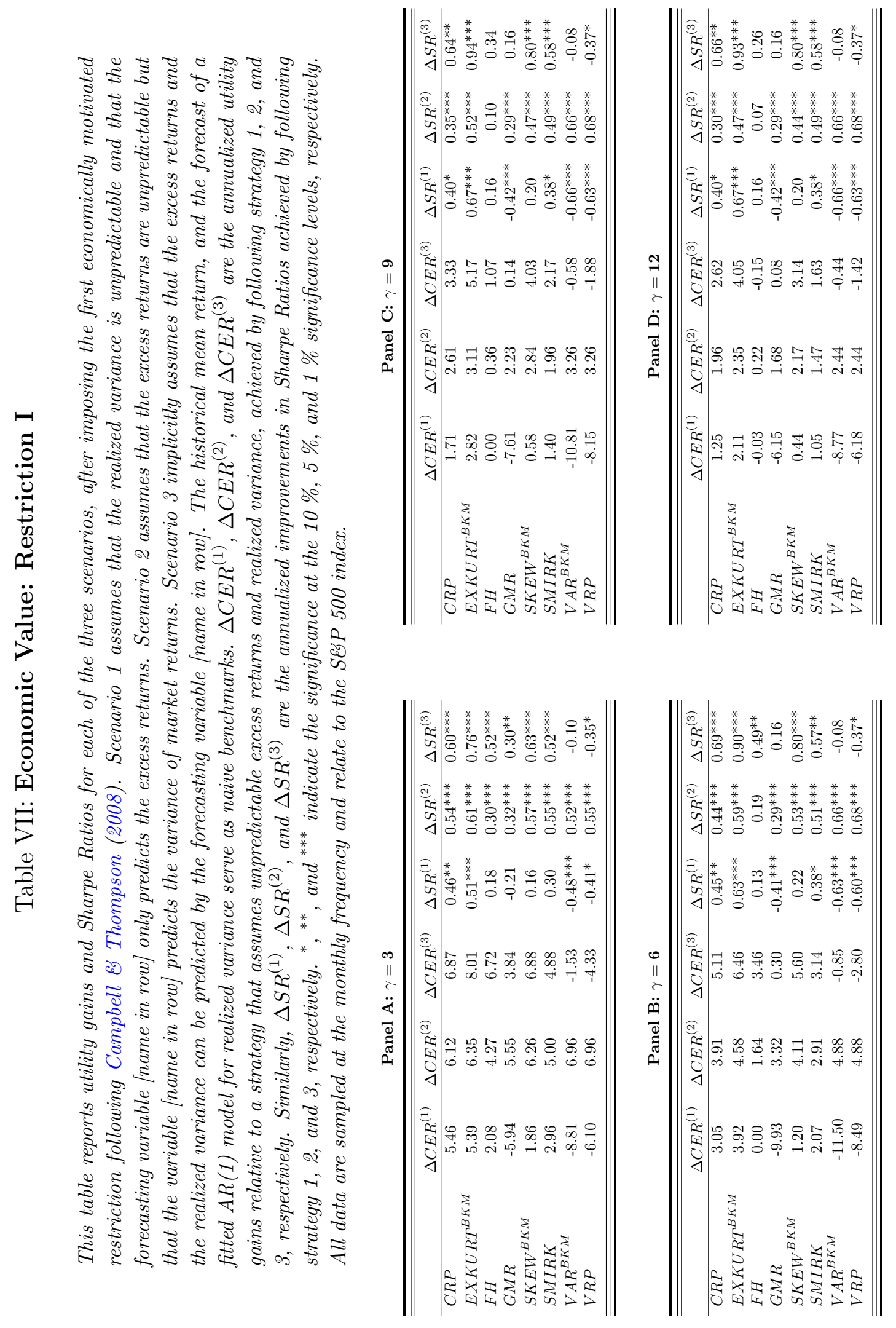



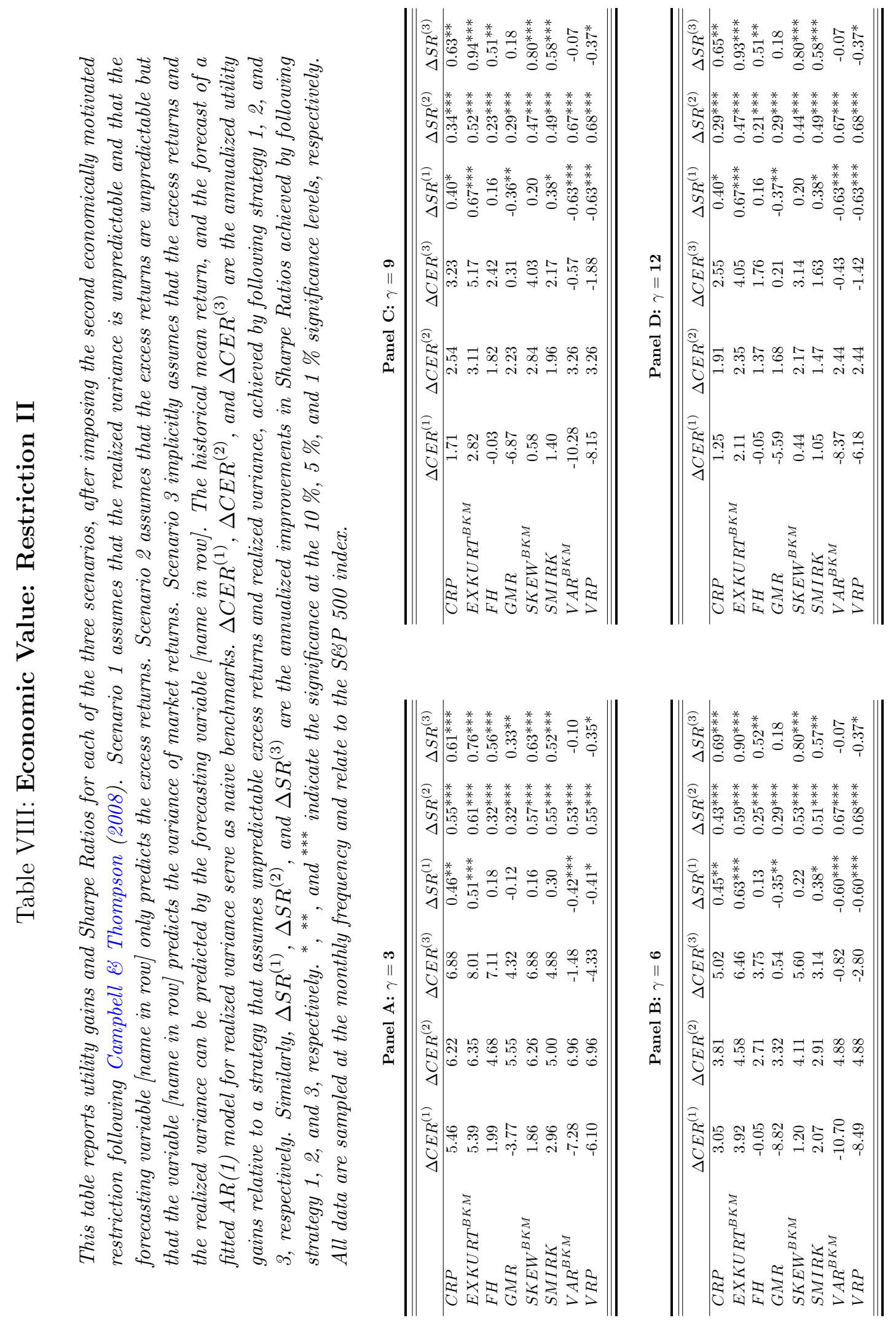


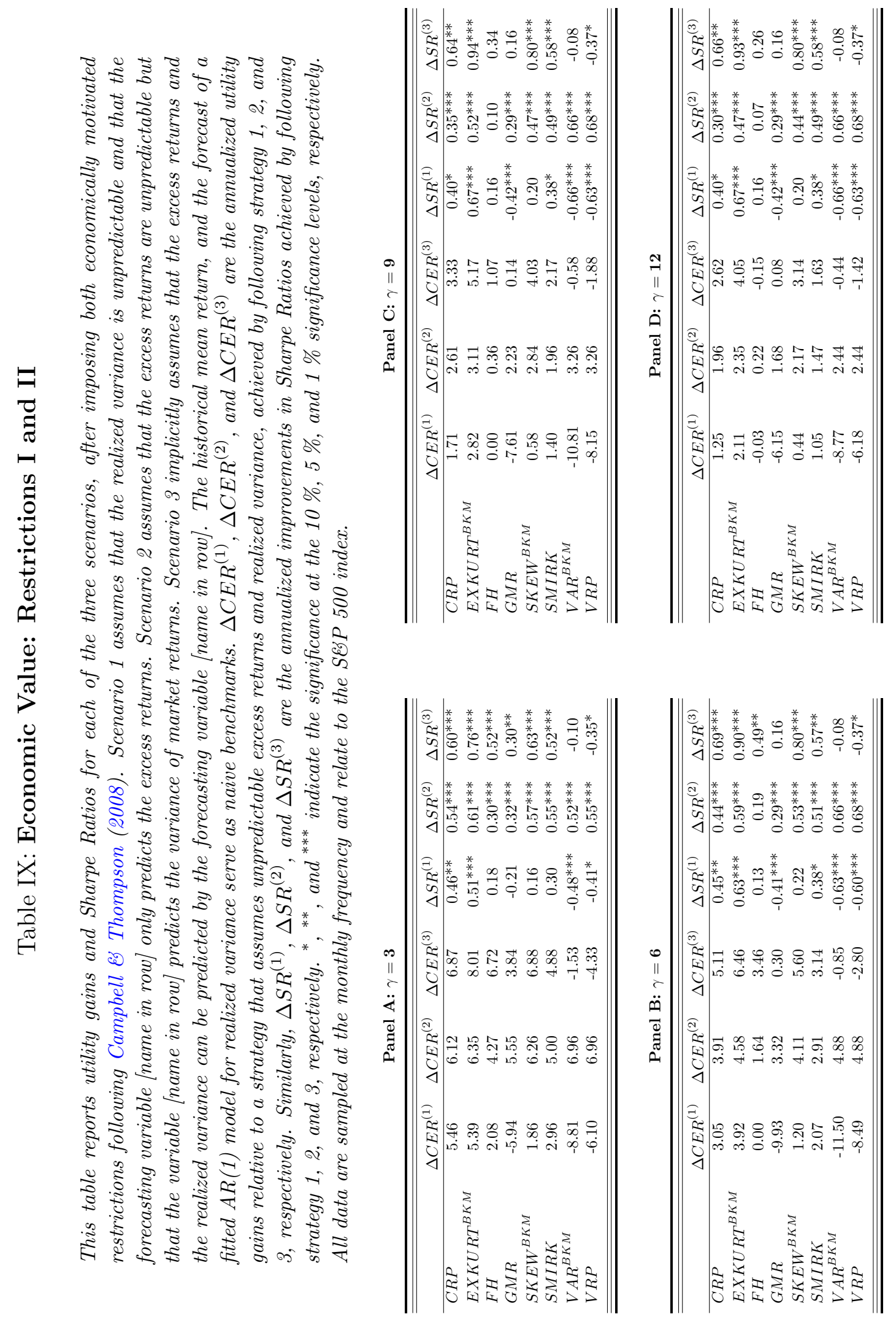




\section{Table X: Out-of-Sample Analysis: Forecast Combinations}

This table reports the results of the out-of-sample analysis after the use of forecast combinations. The mean forecast combination [MeanFC], the median forecast combination [MedianFC], and the trimmed mean forecast combination [TrMeanFC] are used as alternative specifications. We report the MSE-F statistics in parenthesis. The historical mean return, and the forecast of a fitted AR(1) model for realized variance serve as naive benchmarks. Six forecasting variables are used. CRP denotes the correlation risk premium. EXKURT ${ }^{B K M}$ is the risk-neutral kurtosis of Bakshi et al. (2003). FH is the risk-neutral riskiness measure of Leiss $\& 3$ Nax (2018). GMR is the generalized measure of riskiness of Bali et al. (2011). SKEW ${ }^{B K M}$ is the risk-neutral skewness of Bakshi et al. (2003). SMIRK is the option smirk. VAR ${ }^{B K M}$ is the risk-neutral variance of Bakshi et al. (2003). Finally, VRP is the variance risk premium computed as the difference between the risk-neutral variance of Bakshi et al. (2003) and the most recent observation of the realized variance. $R_{\text {oos }}^{2}$ is the out-of-sample $R^{2} .{ }^{*},{ }^{* *}$, and ${ }^{* * *}$ indicate statistical significance at the $10 \%$, $5 \%$, and $1 \%$ significance levels, respectively. All data are sampled at the monthly frequency and relate to the SEP 500 index.

Panel A: Return Predictability

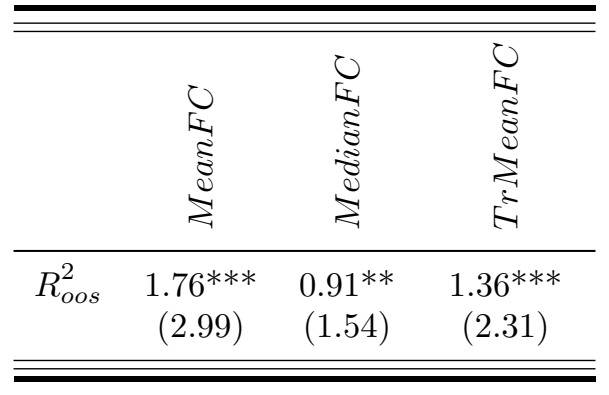

Panel B: Variance Predictability

\begin{tabular}{|c|c|c|c|}
\hline & 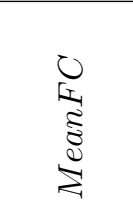 & 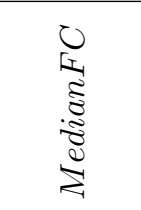 & 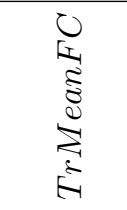 \\
\hline$R_{\text {oos }}^{2}$ & $\begin{array}{c}2.50^{* * * *} \\
(4.28)\end{array}$ & $\begin{array}{c}4.12^{* * *} \\
(7.18)\end{array}$ & $\begin{array}{c}3.06^{* * *} \\
(5.27)\end{array}$ \\
\hline
\end{tabular}




\section{Table XI: Economic Value: Forecast Combinations}

This table reports utility gains and Sharpe Ratios for each of the three scenarios based on forecast combinations. Scenario 1 assumes that realized variance is unpredictable and that the forecast combination only predicts excess returns. Scenario 2 assumes that excess returns are unpredictable but that the forecast combination predicts the variance of market returns. Scenario 3 implicitly assumes that excess returns and variance can be predicted by the forecast combination. The historical mean return and the forecast of a fitted $A R(1)$ model for realized variance serve as naive benchmarks. $\triangle C E R^{(1)}, \triangle C E R^{(2)}$, and $\triangle C E R^{(3)}$ are the annualized utility gains relative to a strategy that assumes unpredictable excess returns and realized variance, achieved by following strategy 1, 2, and 3, respectively. Similarly, $\Delta S R^{(1)}, \Delta S R^{(2)}$, and $\Delta S R^{(3)}$ are the annualized improvements in Sharpe Ratios achieved by following strategy 1, 2, and 3, respectively. ${ }^{*},{ }^{* *}$, and *** indicate the significance at the $10 \%, 5 \%$, and $1 \%$ significance levels, respectively. All data are sampled at the monthly frequency and relate to the SEP 500 index.

Panel A: Mean Forecast Combination

\begin{tabular}{lcccccc}
\hline \hline & $\Delta C E R^{(1)}$ & $\Delta C E R^{(2)}$ & $\Delta C E R^{(3)}$ & $\Delta S R^{(1)}$ & $\Delta S R^{(2)}$ & $\Delta S R^{(3)}$ \\
\hline$\gamma=3$ & 1.21 & 6.07 & 5.80 & 0.11 & $0.50^{* * *}$ & $0.50^{* * *}$ \\
$\gamma=6$ & 0.83 & 3.76 & 3.76 & 0.14 & $0.55^{* * *}$ & $0.60^{* * *}$ \\
$\gamma=9$ & 0.55 & 2.52 & 2.59 & 0.14 & $0.54^{* * *}$ & $0.62^{* * *}$ \\
$\gamma=12$ & 0.41 & 1.89 & 1.94 & 0.14 & $0.54^{* * *}$ & $0.62^{* * *}$ \\
\hline \hline
\end{tabular}

Panel B: Median Forecast Combination

\begin{tabular}{lcccccc}
\hline \hline & $\Delta C E R^{(1)}$ & $\Delta C E R^{(2)}$ & $\Delta C E R^{(3)}$ & $\Delta S R^{(1)}$ & $\Delta S R^{(2)}$ & $\Delta S R^{(3)}$ \\
\hline$\gamma=3$ & 2.00 & 6.08 & 6.22 & 0.18 & $0.54^{* * *}$ & $0.57^{* * *}$ \\
$\gamma=6$ & 0.57 & 3.68 & 3.85 & 0.10 & $0.58^{* * *}$ & $0.64^{* * *}$ \\
$\gamma=9$ & 0.38 & 2.46 & 2.62 & 0.10 & $0.57^{* * *}$ & $0.65^{* * *}$ \\
$\gamma=12$ & 0.28 & 1.85 & 1.96 & 0.10 & $0.57^{* * *}$ & $0.65^{* * *}$ \\
\hline \hline
\end{tabular}

Panel C: Trimmed Mean Forecast Combination

\begin{tabular}{lcccccc}
\hline \hline & $\Delta C E R^{(1)}$ & $\Delta C E R^{(2)}$ & $\Delta C E R^{(3)}$ & $\Delta S R^{(1)}$ & $\Delta S R^{(2)}$ & $\Delta S R^{(3)}$ \\
\hline$\gamma=3$ & 1.63 & 6.05 & 5.94 & 0.14 & $0.52^{* * *}$ & $0.52^{* * *}$ \\
$\gamma=6$ & 0.69 & 3.69 & 3.80 & 0.12 & $0.56^{* * *}$ & $0.62^{* * *}$ \\
$\gamma=9$ & 0.46 & 2.47 & 2.56 & 0.12 & $0.56^{* * *}$ & $0.62^{* * *}$ \\
$\gamma=12$ & 0.34 & 1.86 & 1.92 & 0.12 & $0.56^{* * *}$ & $0.62^{* * *}$ \\
\hline \hline
\end{tabular}




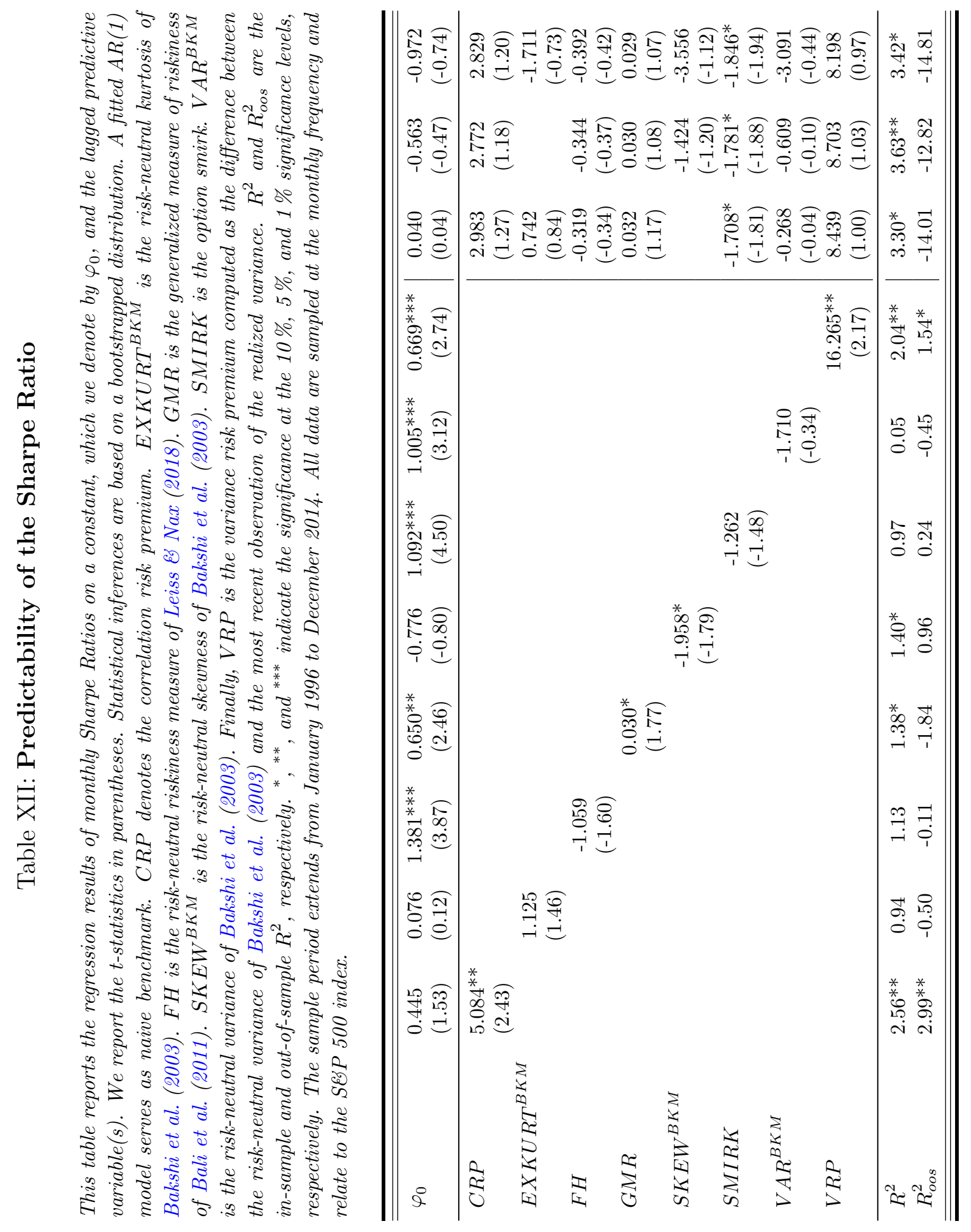




\title{
Predicting the Equity Market with Option-Implied Variables
}

\author{
Fabian Hollstein ${ }^{\dagger}$, Marcel Prokopczuk ${ }^{\dagger, \dagger}$, Björn Tharann $^{\dagger}$, and Chardin \\ Wese Simen ${ }^{\ddagger}$
}

\section{Online Appendix}

JEL classification: G10, G11, G17

Keywords: Equity Premium, Option-Implied Information, Portfolio Choice, Predictability, Timing Strategies

\footnotetext{
${ }^{\dagger}$ School of Economics and Management, Leibniz University Hannover, Koenigsworther Platz 1, 30167 Hannover, Germany.

${ }^{\ddagger}$ ICMA Centre, Henley Business School, University of Reading, Reading, RG6 6BA, UK.
} 


\section{Table A1: Economic Value with Turnover and Transaction Costs}

This table reports the turnover, the utility gains, and the Sharpe Ratios for each of the three scenarios. Scenario 1 assumes that the realized variance is unpredictable and that the forecasting variable [name in column] only predicts the excess returns. Scenario 2 assumes that the excess returns are unpredictable but that the variable [name in column] and the lagged realized variance predict the realized variance. Scenario 3 implicitly assumes that the excess returns and the realized variance can be predicted by the forecasting variable [name in column], and in the latter case, by the forecasting variable [name in column] and the lagged realized variance. The historical mean return, and the forecast of a fitted AR(1) model for realized variance serve as naive benchmarks. Turnover $_{\text {abs }}$ is the monthly absolute value of the turnover for the naive strategy. Turnover $r_{r e l}^{(i)}$ represents the monthly relative turnover of strategy $i$ related to the benchmark. $\triangle C E R^{(1)}$, $\triangle C E R^{(2)}$, and $\triangle C E R^{(3)}$ are the annualized utility gains relative to a strategy that assumes unpredictable excess returns and realized variance, achieved by following strategy 1, 2, and 3, respectively. Similarly, $\Delta S R^{(1)}, \Delta S R^{(2)}$, and $\Delta S R^{(3)}$ are the annualized improvements in Sharpe Ratios achieved by following strategy 1, 2, and 3, respectively. ${ }^{*},{ }^{* *}$, and ${ }^{* * *}$ indicate the significance at the $10 \%, 5 \%$, and $1 \%$ significance levels, respectively. All data are sampled at the monthly frequency and relate to the SESP 500 index.

Panel A: $\gamma=\mathbf{3}$

\begin{tabular}{lcccccccc}
\hline \hline & $C R P$ & $E X K U R T^{B K M}$ & $F H$ & $G M R$ & $S K E W^{B K M}$ & $S M I R K$ & $V A R^{B K M}$ & $V R P$ \\
\hline Turnover $_{\text {abs }}$ & 0.0448 & 0.0448 & 0.0448 & 0.0448 & 0.0448 & 0.0448 & 0.0448 & 0.0448 \\
Turnover $_{\text {rel }}^{(1)}$ & 12.1906 & 5.4513 & 4.5365 & 3.0830 & 5.5545 & 8.9341 & 2.2193 & 9.6821 \\
Turnover rel $_{\text {rel }}^{(2)}$ & 4.8831 & 5.5580 & 1.2842 & 2.0465 & 2.9157 & 2.7424 & 2.7127 & 3.9283 \\
Turnover $_{\text {rel }}^{(3)}$ & 14.6331 & 8.2202 & 4.1985 & 2.0576 & 6.6146 & 10.9321 & 3.4473 & 11.5826 \\
$\Delta$ CER $^{(1)}$ & 2.48 & 4.19 & 1.03 & -4.31 & 0.64 & 0.85 & -7.62 & -8.46 \\
$\Delta$ CER $^{(2)}$ & -1.03 & 1.60 & 1.43 & 4.39 & 1.81 & 1.87 & 5.94 & 7.04 \\
$\Delta$ CER $^{(3)}$ & 1.38 & 4.46 & 3.17 & 2.36 & 2.33 & 0.55 & -4.91 & -5.47 \\
$\Delta$ SR $^{(1)}$ & 0.21 & $0.39^{* *}$ & 0.12 & -0.14 & 0.06 & 0.05 & $-0.43^{* * *}$ & $-0.57^{* * *}$ \\
$\Delta S R^{(2)}$ & 0.06 & 0.20 & $0.12^{*}$ & $0.24^{* * *}$ & 0.21 & $0.21^{* *}$ & $0.36^{* * *}$ & $0.47^{* * *}$ \\
$\Delta S R^{(3)}$ & 0.13 & $0.36^{*}$ & $0.26^{* *}$ & $0.22^{*}$ & 0.20 & 0.06 & -0.22 & -0.25 \\
\hline \hline
\end{tabular}

Panel B: $\gamma=6$

\begin{tabular}{|c|c|c|c|c|c|c|c|c|}
\hline & $C R P$ & $E X K U R T^{B K M}$ & $F H$ & $G M R$ & $S K E W^{B K M}$ & $S M I R K$ & $V A R^{B K M}$ & $V R P$ \\
\hline Turnover $_{a b s}$ & 0.0247 & 0.0247 & 0.0247 & 0.0247 & 0.0247 & 0.0247 & 0.0247 & 0.0247 \\
\hline Turnover & 15.9051 & 7.0084 & 5.7696 & 5.5303 & 7.0350 & 9.3238 & 4.2300 & 12.5610 \\
\hline Turnover & 10.6311 & 10.8603 & 2.2327 & 2.5870 & 6.8986 & 4.7041 & 5.8114 & 9.8254 \\
\hline Turnover & 25.8225 & 16.2198 & 8.4137 & 5.2987 & 13.7024 & 18.2632 & 5.2006 & 18.7912 \\
\hline$\Delta C E R^{(1)}$ & 0.88 & 3.03 & -0.79 & -9.52 & 0.30 & 0.85 & -11.25 & -10.32 \\
\hline$\Delta C E R^{(2)}$ & -5.70 & 0.95 & -1.58 & 2.76 & 0.29 & 0.26 & 4.83 & 4.18 \\
\hline$\Delta C E R^{(3)}$ & -1.36 & 2.62 & -0.68 & -3.30 & 0.64 & -0.28 & -6.18 & -10.91 \\
\hline$\Delta S R^{(1)}$ & 0.18 & $0.49^{* * *}$ & 0.07 & $-0.38^{* * *}$ & 0.10 & 0.10 & $-0.61^{* * *}$ & $-0.73^{* * *}$ \\
\hline$\Delta S R^{(2)}$ & -0.14 & 0.25 & 0.02 & $0.21^{* * *}$ & $0.20^{*}$ & 0.16 & $0.44^{* * *}$ & $0.49^{* * *}$ \\
\hline$\Delta S R^{(3)}$ & 0.12 & $0.41^{*}$ & 0.22 & 0.08 & 0.27 & 0.06 & -0.28 & $-0.54^{* *}$ \\
\hline
\end{tabular}




\section{Table A1: Economic Value with Turnover and Transaction Costs (continued)}

\begin{tabular}{lcccccccc}
\multicolumn{1}{c}{ Panel C: $\gamma=\mathbf{9}$} \\
\hline \hline & $C R P$ & $E X K U R T^{B K M}$ & $F H$ & $G M R$ & $S K E W^{B K M}$ & SMIRK & $V A R^{\text {BKM }}$ & $V R P$ \\
\hline Turnover $_{\text {abs }}$ & 0.0151 & 0.0151 & 0.0151 & 0.0151 & 0.0151 & 0.0151 & 0.0151 & 0.0151 \\
Turnover $_{\text {rel }}$ & 18.4886 & 8.8266 & 7.1716 & 6.7321 & 9.2375 & 10.2124 & 5.7328 & 15.0938 \\
Turnover $_{\text {rel }}$ & 15.6516 & 16.8364 & 3.4586 & 2.6537 & 10.1848 & 5.1486 & 6.6592 & 17.8674 \\
Turnover $_{\text {rel }}^{(3)}$ & 36.6566 & 26.1824 & 11.1854 & 7.8807 & 20.6825 & 24.7431 & 5.7841 & 22.0822 \\
$\Delta C E R^{(1)}$ & 0.15 & 2.11 & -0.62 & -7.43 & -0.18 & 0.57 & -10.81 & -9.58 \\
$\Delta C E R^{(2)}$ & -6.59 & 0.70 & -2.11 & 1.82 & 0.03 & 0.13 & 3.25 & 2.20 \\
$\Delta C E R^{(3)}$ & -2.17 & 1.01 & -3.55 & -4.35 & -1.03 & -0.41 & -4.53 & -9.70 \\
$\Delta S R^{(1)}$ & 0.13 & $0.50^{* * *}$ & 0.08 & $-0.40^{* * *}$ & 0.07 & 0.10 & $-0.65^{* * *}$ & $-0.74^{* * *}$ \\
$\Delta S R^{(2)}$ & -0.18 & $0.25^{*}$ & -0.01 & $0.18^{* * *}$ & $0.18^{*}$ & 0.14 & $0.44^{* * *}$ & $0.49^{* * *}$ \\
$\Delta S R^{(3)}$ & 0.14 & 0.39 & 0.07 & -0.01 & 0.22 & 0.10 & -0.29 & $-0.59^{* * *}$ \\
\hline \hline
\end{tabular}

Panel D: $\gamma=12$

\begin{tabular}{lcccccccc}
\hline \hline & $C R P$ & $E X K U R T^{B K M}$ & $F H$ & GMR & SKEW & EKM & SMIRK & VAR \\
\hline Turnover $_{\text {abs }}$ & 0.0108 & 0.0108 & 0.0108 & 0.0108 & 0.0108 & 0.0108 & 0.0108 & 0.0108 \\
Turnover $_{\text {rel }}$ & 19.5157 & 9.1852 & 7.4131 & 7.4079 & 10.0488 & 10.6805 & 6.4946 & 15.8094 \\
Turnover $_{\text {rel }}$ & 18.2998 & 21.0369 & 4.5438 & 2.6821 & 12.2949 & 5.3345 & 6.8723 & 24.3221 \\
Turnover $_{\text {rel }}^{(3)}$ & 45.3856 & 34.0648 & 12.6527 & 9.0251 & 25.9198 & 27.6275 & 6.0582 & 23.5223 \\
$\Delta C E R^{(1)}$ & 0.07 & 1.58 & -0.49 & -6.05 & -0.17 & 0.43 & -8.86 & -7.25 \\
$\Delta C E R^{(2)}$ & -7.04 & 0.49 & -2.40 & 1.36 & -0.24 & 0.08 & 2.43 & 0.77 \\
$\Delta C E R^{(3)}$ & -2.90 & 0.09 & -4.75 & -3.49 & -1.78 & -0.48 & -3.45 & -8.30 \\
$\Delta S R^{(1)}$ & 0.12 & $0.50^{* * *}$ & 0.08 & $-0.41^{* * *}$ & 0.07 & 0.10 & $-0.65^{* * *}$ & $-0.75^{* * *}$ \\
$\Delta S R^{(2)}$ & -0.21 & $0.25^{*}$ & -0.04 & $0.18^{* * *}$ & 0.14 & 0.13 & $0.44^{* * *}$ & $0.43^{* *}$ \\
$\Delta S R^{(3)}$ & 0.11 & 0.38 & -0.01 & -0.01 & 0.21 & 0.09 & -0.29 & $-0.59^{* * *}$ \\
\hline \hline \hline
\end{tabular}




\section{Table A2: Out-of-Sample Analysis: Restriction - Frequencies}

This table reports the absolute frequency of how often the economically motivated restrictions imposed are binding in the out-of-sample analysis, shown in Table VI. Panel A shows the frequency for each individual variable, predicting the next month's excess return. Panel B shows the frequency for each individual variable as well as lagged realized variance, predicting the next month's realized variance. CRP denotes the correlation risk premium. EXKURT ${ }^{B K M}$ is the risk-neutral kurtosis of Bakshi et al. (2003). FH is the risk-neutral riskiness measure of Leiss \& Nax (2018). GMR is the generalized measure of riskiness of Bali et al. (2011). SKEW ${ }^{B K M}$ is the risk-neutral skewness of Bakshi et al. (2003). SMIRK is the option smirk. VAR ${ }^{B K M}$ is the risk-neutral variance of Bakshi et al. (2003). Finally, VRP is the variance risk premium computed as the difference between the risk-neutral variance of Bakshi et al. (2003) and the most recent observation of the realized variance. The historical mean return, and the forecast of a fitted $A R(1)$ model for realized variance serve as naive benchmarks. "(I)" denotes the imposition of the first restriction, where we set the slope estimate in the out-of-sample analysis equal to zero, whenever its sign differs from that of the in-sample analysis. "(II)" denotes the imposition of the second restriction, where we set the forecast equal to zero, whenever it is negative. " $(I+I I)$ " denotes the joint imposition of both restrictions. "(I+II) (I)" ("(I+II) (II)") refers to the frequency of the first (second) restriction in the case of the joint imposition of both restrictions. All data are sampled at the monthly frequency and relate to the SEP 500 index.

Panel A: Return Predictability

\begin{tabular}{|c|c|c|c|c|c|c|c|c|c|}
\hline & & $\frac{\hat{\sigma}}{\sigma}$ & 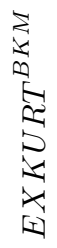 & $\underset{E}{\mathbb{E}}$ & 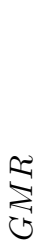 & 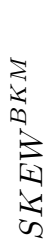 & $\underset{\infty}{\stackrel{\Xi}{E}}$ & 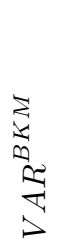 & $\frac{Q}{2}$ \\
\hline (I) & & 0 & 0 & 12 & 8 & 0 & 0 & 35 & 0 \\
\hline (II) & & 53 & 32 & 8 & 7 & 29 & 62 & 56 & 77 \\
\hline$(\mathrm{I}+\mathrm{II})$ & (I) & 0 & 0 & 12 & 8 & 0 & 0 & 35 & 0 \\
\hline$(\mathrm{I}+\mathrm{II})$ & (II) & 53 & 32 & 9 & 0 & 29 & 62 & 50 & 77 \\
\hline
\end{tabular}

Panel B: Variance Predictability

\begin{tabular}{|c|c|c|c|c|c|c|c|c|c|}
\hline & & $\frac{\hat{\sigma}}{\sigma}$ & 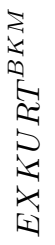 & $\frac{\nabla}{1}$ & $\underset{\mho}{\underset{Z}{\sigma}}$ & 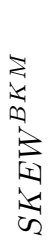 & $\frac{\vec{Z}}{\sum_{\infty}}$ & 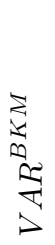 & $\frac{B}{D}$ \\
\hline (I) & & 75 & 0 & 76 & 3 & 0 & 0 & 0 & 0 \\
\hline (II) & & 0 & 3 & 0 & 0 & 0 & 0 & 0 & 0 \\
\hline$(\mathrm{I}+\mathrm{II})$ & (I) & 75 & 0 & 76 & 3 & 0 & 0 & 0 & 0 \\
\hline$(\mathrm{I}+\mathrm{II})$ & (II) & 0 & 3 & 0 & 0 & 0 & 0 & 0 & 0 \\
\hline
\end{tabular}

Lagged Realized Variance

\begin{tabular}{llllllllll}
\hline \hline$(\mathrm{I})$ & & 0 & 0 & 0 & 0 & 0 & 0 & 0 & 0 \\
$(\mathrm{II})$ & & - & - & - & - & - & - & - & - \\
$(\mathrm{I}+\mathrm{II})$ & $(\mathrm{I})$ & 0 & 0 & 0 & 0 & 0 & 0 & 0 & 0 \\
$(\mathrm{I}+\mathrm{II})$ & $(\mathrm{II})$ & - & - & - & - & - & - & - & - \\
\hline \hline
\end{tabular}




\section{Table A3: Return and Variance Predictability of $\boldsymbol{V R P}$ Specifications}

Panel $A$ of this table reports the regression results of monthly excess returns on a constant, which we denote by $\beta_{0}$, and the lagged predictive variable. Panel $B$ reports the regression results of monthly realized variance on a constant, which we denote by $\gamma_{0}$, the lagged predictive variable, and the lagged realized variance. Statistical inferences are based on a bootstrapped distribution. The historical mean return, and the forecast of a fitted AR(1) model for realized variance serve as naive benchmarks. $V R P^{H A R}$ denotes the variance risk premium based on the HAR-RV model. $V R P^{D O W N}$ is the downside variance risk premium. $V R P^{U P}$ is the upside variance risk premium. $V R P^{D O W N, H A R}$ is the downside variance risk premium based on the HAR-RV model. Finally, $V R P^{U P, H A R}$ is the upside variance risk premium based on the $H A R-R V$ model. $R^{2}$ and $R_{\text {oos }}^{2}$ are the in-sample and out-of-sample $R^{2}$, respectively. We report the t-statistics in parentheses. ${ }^{*},{ }^{* *}$, and $^{* * *}$ indicate the significance at the 10\%, 5\%, and 1\% significance levels, respectively. The sample period extends from January 1996 to December 2014. All data are sampled at the monthly frequency and relate to the SEP 500 index.

Panel A: Return Predictability

\begin{tabular}{|c|c|c|c|c|c|}
\hline & 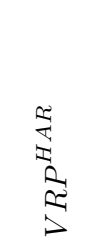 & $\begin{array}{l}z \\
z \\
0 \\
0 \\
a \\
a \\
1 \\
1\end{array}$ & $\begin{array}{l}a \\
i \\
\hat{a} \\
1 \\
1\end{array}$ & 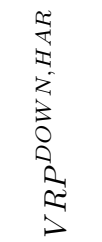 & 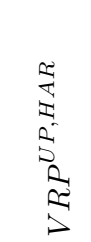 \\
\hline$R^{2}$ & 0.00 & $2.23^{* *}$ & $2.65^{* *}$ & 0.38 & $2.05^{* *}$ \\
\hline $\begin{array}{l}R_{o o s}^{2} \\
t-s t a t\end{array}$ & $\begin{array}{l}-5.37 \\
(0.10)\end{array}$ & $\begin{array}{l}-1.13 \\
(2.26)\end{array}$ & $\begin{array}{l}-2.38 \\
(2.47)\end{array}$ & $\begin{array}{l}-4.10 \\
(0.93)\end{array}$ & $\begin{array}{l}-1.25 \\
(2.17)\end{array}$ \\
\hline
\end{tabular}

Panel B: Variance Predictability

\begin{tabular}{|c|c|c|c|c|c|}
\hline & 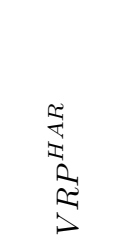 & $\begin{array}{l}z \\
3 \\
0 \\
0 \\
0 \\
2 \\
1\end{array}$ & $\begin{array}{l}2 \\
i \\
2 \\
2 \\
1\end{array}$ & 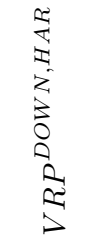 & 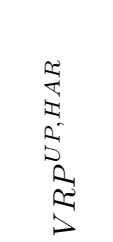 \\
\hline$R^{2}$ & 42.95 & 41.03 & 40.34 & 41.19 & 43.94 \\
\hline $\begin{array}{l}R_{\text {oos }}^{2} \\
t-s t a t\end{array}$ & $\begin{array}{c}3.40 * * * \\
(3.32)\end{array}$ & $\begin{array}{c}4.34^{* * *} \\
(1.85)\end{array}$ & $\begin{array}{l}-3.46 \\
(0.89)\end{array}$ & $\begin{array}{l}-4.05 \\
(2.01)\end{array}$ & $\begin{array}{c}4.63 * * * \\
(3.90)\end{array}$ \\
\hline
\end{tabular}




\section{Table A4: Economic Value of $\boldsymbol{V R P}$ Specifications}

This table reports utility gains and Sharpe Ratios for each of the three scenarios. Scenario 1 assumes that the realized variance is unpredictable and that the forecasting variable [name in column] only predicts the excess returns. Scenario 2 assumes that the excess returns are unpredictable but that the variable [name in column] and the lagged realized variance predict the realized variance. Scenario 3 implicitly assumes that the excess returns and the realized variance can be predicted by the forecasting variable [name in column], and in the latter case, by the forecasting variable [name in column] and the lagged realized variance. The historical mean return, and the forecast of a fitted $A R(1)$ model for realized variance serve as naive benchmarks. $\triangle C E R^{(1)}, \triangle C E R^{(2)}$, and $\triangle C E R^{(3)}$ are the annualized utility gains relative to a strategy that assumes unpredictable excess returns and realized variance, achieved by following strategy 1, 2, and 3, respectively. Similarly, $\Delta S R^{(1)}, \Delta S R^{(2)}$, and $\Delta S R^{(3)}$ are the annualized improvements in Sharpe Ratios achieved by following strategy 1, 2, and 3, respectively. ${ }^{*},{ }^{* *}$, and ${ }^{* * *}$ indicate the significance at the $10 \%, 5 \%$, and $1 \%$ significance levels, respectively. All data are sampled at the monthly frequency and relate to the S\&P 500 index.

Panel A: $\gamma=\mathbf{3}$

\begin{tabular}{|c|c|c|c|c|c|}
\hline & 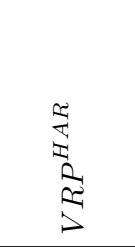 & $\begin{array}{l}z \\
\vdots \\
0 \\
0 \\
a \\
a \\
1 \\
1\end{array}$ & $\begin{array}{l}2 \\
5 \\
\frac{1}{2} \\
1\end{array}$ & $\begin{array}{l}2 \\
2 \\
2 \\
2 \\
3 \\
0 \\
0 \\
0 \\
2 \\
2 \\
12\end{array}$ & 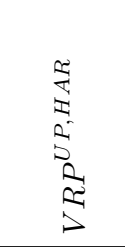 \\
\hline$\Delta C E R^{(1)}$ & -7.41 & 0.24 & 2.25 & -9.33 & -9.25 \\
\hline$\Delta C E R^{(2)}$ & 6.29 & 7.40 & 6.73 & 5.17 & 5.11 \\
\hline$\Delta C E R^{(3)}$ & -4.36 & 6.31 & 6.74 & -4.99 & -8.24 \\
\hline$\Delta S R^{(1)}$ & $-0.43^{* * *}$ & 0.04 & $0.19^{* *}$ & $-0.55^{* * *}$ & $-0.58 * * *$ \\
\hline$\Delta S R^{(2)}$ & $0.38^{* * *}$ & $0.69^{* * *}$ & $0.71^{* * *}$ & $0.37^{* * *}$ & $0.40^{* * *}$ \\
\hline$\Delta S R^{(3)}$ & -0.20 & $0.59^{* * *}$ & $0.71^{* * *}$ & $-0.29^{*}$ & $-0.51^{* *}$ \\
\hline
\end{tabular}

Panel B: $\gamma=6$

\begin{tabular}{|c|c|c|c|c|c|}
\hline & 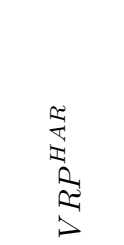 & $\begin{array}{l}z \\
3 \\
0 \\
0 \\
0 \\
a \\
1 \\
1\end{array}$ & $\begin{array}{l}a \\
5 \\
\vec{a} \\
1 \\
1\end{array}$ & $\begin{array}{l} \\
2 \\
\vdots \\
z \\
3 \\
0 \\
0 \\
0 \\
0 \\
2 \\
1 \\
1\end{array}$ & 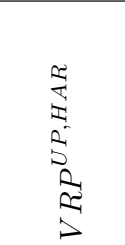 \\
\hline$\Delta C E R^{(1)}$ & -10.71 & -1.91 & 0.96 & -11.09 & -10.73 \\
\hline$\Delta C E R^{(2)}$ & 5.47 & 5.94 & 5.12 & 3.70 & 4.81 \\
\hline$\Delta C E R^{(3)}$ & -6.36 & 4.47 & 6.13 & -6.32 & -8.17 \\
\hline$\Delta S R^{(1)}$ & $-0.60 * * *$ & -0.12 & $0.17^{*}$ & $-0.64^{* * *}$ & $-0.69^{* * *}$ \\
\hline$\Delta S R^{(2)}$ & $0.46^{* * *}$ & $0.74^{* * *}$ & $0.60 * * *$ & $0.40^{* * *}$ & $0.62 * * *$ \\
\hline$\Delta S R^{(3)}$ & -0.27 & $0.61^{* *}$ & $0.79^{* * *}$ & $-0.37^{* *}$ & $-0.59 * * *$ \\
\hline
\end{tabular}


Table A4: Economic Value of $\boldsymbol{V R P}$ Specifications (continued)

\begin{tabular}{|c|c|c|c|c|c|}
\hline \multicolumn{6}{|c|}{ Panel C: $\gamma=\mathbf{9}$} \\
\hline & 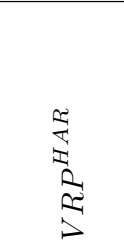 & $\begin{array}{l}z \\
b \\
0 \\
0 \\
\overrightarrow{2} \\
\overrightarrow{1} \\
1\end{array}$ & $\begin{array}{l}a \\
\vdots \\
\hat{2} \\
1 \\
1\end{array}$ & 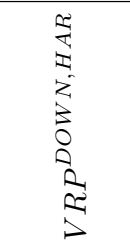 & 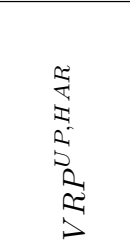 \\
\hline$\Delta C E R^{(1)}$ & -10.65 & -2.43 & 0.63 & -10.89 & -9.83 \\
\hline$\Delta C E R^{(2)}$ & 3.72 & 4.24 & 3.21 & 2.49 & 4.36 \\
\hline$\Delta C E R^{(3)}$ & -4.72 & 3.39 & 4.63 & -5.68 & -6.97 \\
\hline$\Delta S R^{(1)}$ & $-0.62^{* * *}$ & -0.21 & $0.17^{*}$ & $-0.65^{* * *}$ & $-0.73^{* * *}$ \\
\hline$\Delta S R^{(2)}$ & $0.47^{* * *}$ & $0.67^{* * *}$ & $0.45^{* *}$ & $0.36^{* * *}$ & $0.76^{* * *}$ \\
\hline$\Delta S R^{(3)}$ & -0.29 & $0.64^{* *}$ & $0.80^{* * *}$ & $-0.40^{* *}$ & $-0.60 * * *$ \\
\hline
\end{tabular}

Panel D: $\gamma=12$

\begin{tabular}{|c|c|c|c|c|c|}
\hline & 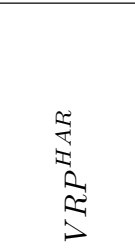 & $\begin{array}{l}2 \\
3 \\
0 \\
2 \\
2 \\
2 \\
1\end{array}$ & $\begin{array}{l}a \\
5 \\
\overrightarrow{2} \\
1 \\
1\end{array}$ & 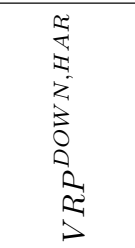 & 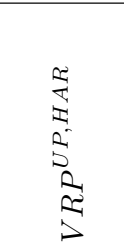 \\
\hline$\Delta C E R^{(1)}$ & -8.65 & -2.20 & 0.47 & -10.35 & -7.82 \\
\hline$\Delta C E R^{(2)}$ & 2.78 & 3.15 & 2.25 & 1.85 & 3.43 \\
\hline$\Delta C E R^{(3)}$ & -3.60 & 2.53 & 3.25 & -4.61 & -5.49 \\
\hline$\Delta S R^{(1)}$ & $-0.63^{* * *}$ & $-0.23^{*}$ & $0.17^{*}$ & $-0.62 * * *$ & $-0.72^{* * *}$ \\
\hline$\Delta S R^{(2)}$ & $0.47^{* * *}$ & $0.61^{* * *}$ & $0.43^{*}$ & $0.34^{* * *}$ & $0.80^{* * *}$ \\
\hline$\Delta S R^{(3)}$ & -0.29 & $0.65^{* *}$ & $0.76^{* *}$ & $-0.40^{* *}$ & $-0.59 * * *$ \\
\hline
\end{tabular}




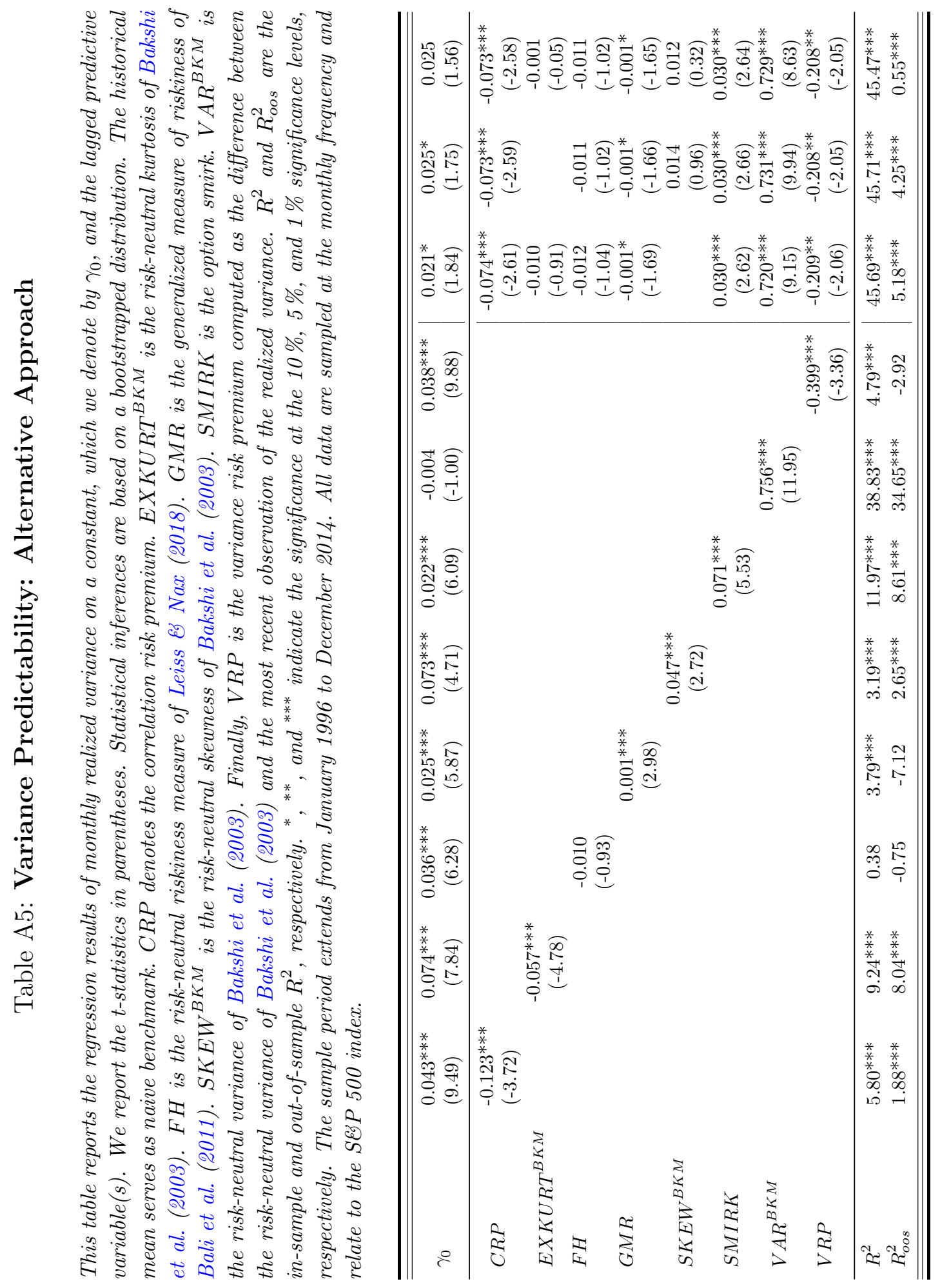




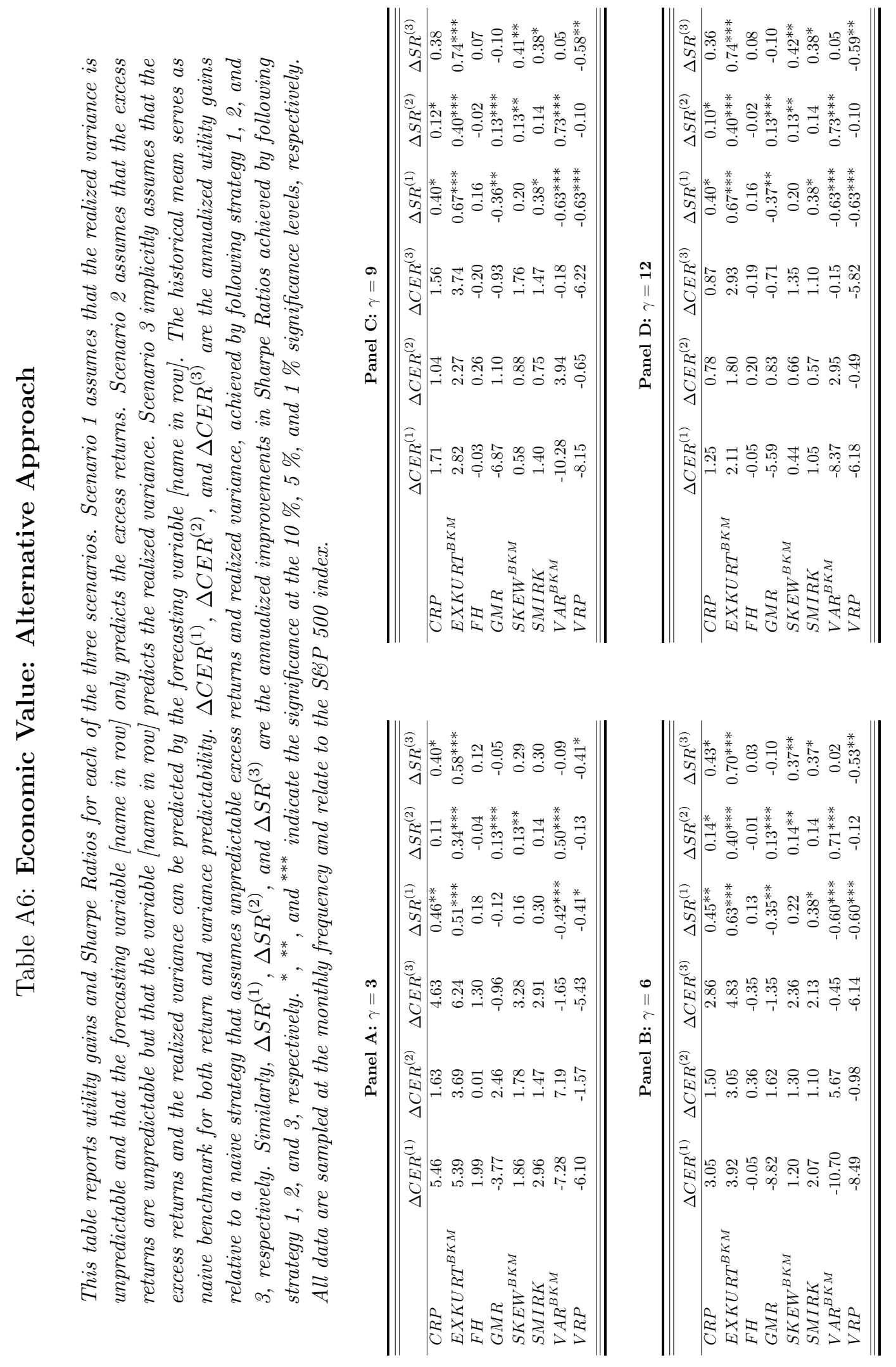

